\title{
HILGARDIA
}

A Journal of Agricultural Science Published by the California Agricultural Experiment Station

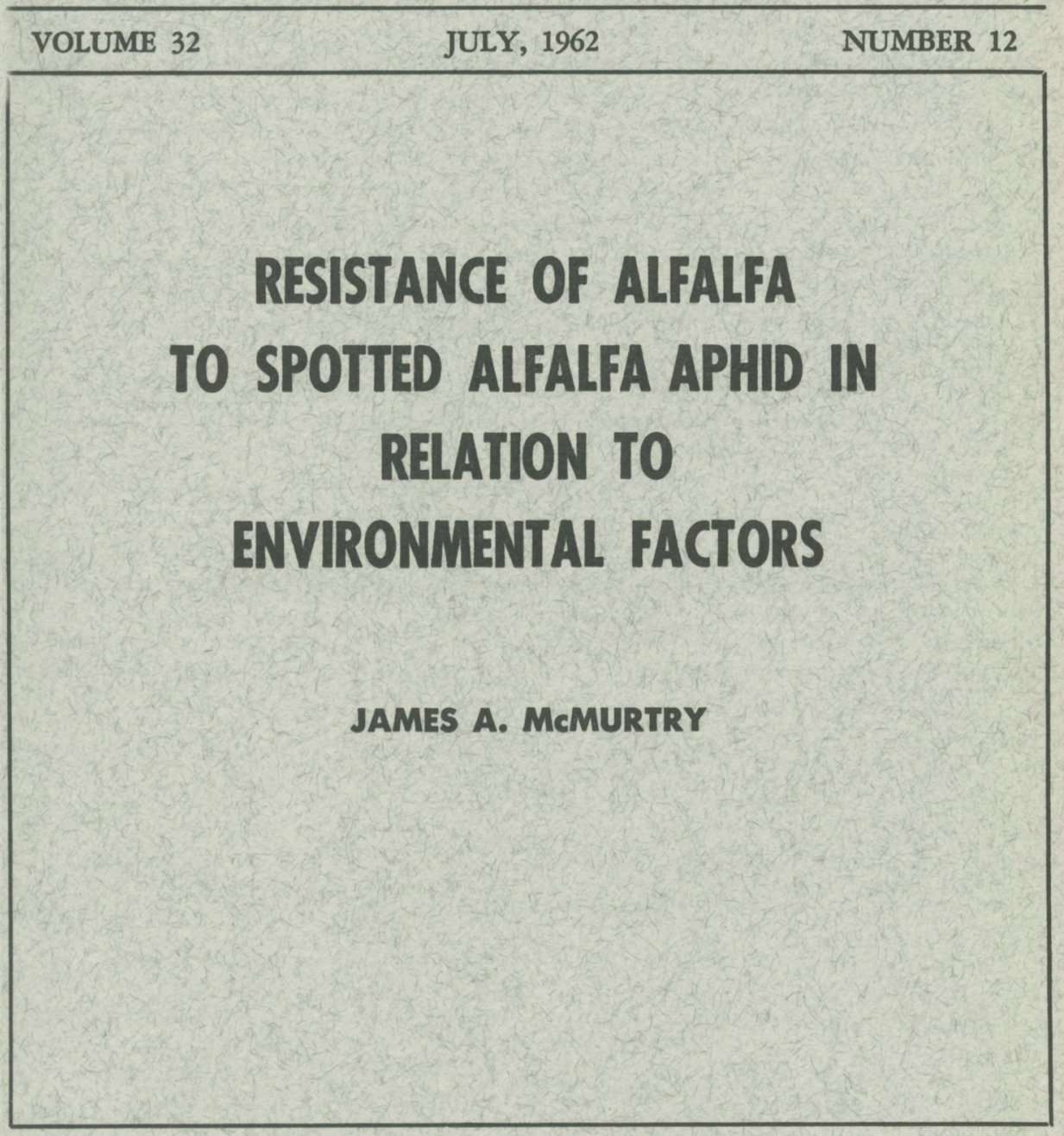

UNIVERSITY OF CALIFORNIA - BERKELEY, CALIFORNIA 
Resistance in alfalfa to the spotted alfalfa aphid, Therioaphis maculata (Buckton), was studied in relation to several environmental factors. Two resistant parental clones of the variety Lahontan were studied in comparison with a susceptible variety, Caliverde. The two Lahontan clones showed a lower degree of resistance at low than at high temperatures. One clone, C-902, appeared to be completely susceptible at $50^{\circ}$ and $60^{\circ} \mathrm{F}$, but became progressively more resistant at higher temperatures. The other clone, C-84, maintained at least an intermediate degree of resistance even at $50^{\circ} \mathrm{F}$, and was usually immune to aphid infestation at temperatures of $68^{\circ} \mathrm{F}$ or higher. The decrease in expression of resistance at low temperatures was shown to be due mainly to a change in the resistant plant, which in turn affected aphid survival and reproduction. Only a few days' time was required for resistance to become reduced at low temperatures or regained at high temperatures. Under controlled conditions of alternating high and low temperatures, the mean rather than the high or the low temperature appeared to be the most important in controlling the degree of resistance expressed. Differences in photoperiod apparently had no effect on aphid survival and reproduction. C-84 and C-902 plants watered with phosphorus- or potassium-deficient nutrient solutions were significantly different in resistance from plants watered with complete nutrient solutions. Phosphorusdeficient plants became more resistant, and potassium-deficient plants became less resistant. Susceptibility of Caliverde plants was not affected. 


\title{
$\begin{array}{lllllllll}H & I & L & G & A & R & D & I & A\end{array}$
}

A Journal of Agricultural Science Published by

the California Agricultural Experiment Station

VoL. 32

JULY, 1962

No. 12

\section{RESISTANCE Of ALFALFA TO SPOTted ALFALFA APHID IN RELATION TO ENVIRONMENTAL FACTORS ${ }^{1,2}$}

\author{
JAMES A. MCMURTRY
}

\section{INTRODUCTION}

The SPOTted alfalfa aPHID, Therioaphis maculata (Buckton), was first observed in damaging numbers in New Mexico in the fall of 1953 (Dobson and Watts, 1957)..$^{4}$ Early the following year, it was also observed damaging alfalfa in parts of Arizona and southern California, and was then recognized as being a new pest (Dickson, Laird, and Pesho, 1955). Its spread from that area occurred at a spectacular rate, and the pest is now found in nearly all of the alfalfa-producing regions of the United States. In California, it had infested 97.5 per cent of the alfalfa acreage and caused over 35 million dollars in direct damage and control costs in a span of four years (Smith, 1959).

As a result of the tremendous economic losses caused by the spotted alfalfa aphid, an intensive control program was initiated by state and federal workers at many experiment stations throughout the United States. Along with studies of chemical and biological control, the possibility of finding alfalfa varieties resistant to the aphid was also investigated. Harpaz (1955) in Israel had observed differential population levels of the spotted alfalfa aphid on different varieties. In some alfalfa varietal nurseries in California and Nevada it was noted that plantings of the variety Lahontan showed little injury from the spotted alfalfa aphid, while those of other varieties in the same plot were often completely killed (Stanford, 1956).

Thus, a commercial variety of alfalfa which possessed resistance to the spotted alfalfa aphid was already in existence. However, the adaptability of Lahontan is limited; consequently, its quality and yield are unsatisfactory in many areas (Stanford, 1956). Other varieties, such as Nemastan and C-104, have since been found to possess some degree of resistance to the aphid (Hackerott et al., 1958). Also, some resistant plants have been found to occur within susceptible varieties (Harvey and Hackerott, 1956). The

\footnotetext{
${ }^{1}$ Submitted for publication March 27, 1961.

${ }^{2}$ Paper No. 1359, University of California, Citrus Research Center and Agricultural Experiment Station, Riverside.

${ }^{3}$ Assistant Entomologist in Biological Control, Citrus Research Center and Agricultural Experiment Station, Riverside.

"See "Literature Cited" for citations referred to in the text by author and date.
} 
existence of such known sources of resistance has made it possible to carry out alfalfa breeding programs for developing varieties which have aphid resistance as well as adaptability to a particular area. Three such varietiesMoapa, Cody, and Zia-have already been released for commercial planting.

Resistance of plants to insect attack has been defined by Painter (1951) as "the relative amount of heritable qualities possessed by the plant which influence the ultimate degree of damage done by the insect." In the same reference, Painter has divided the types of plant resistance to insects into three main categories: preference, antibiosis, and tolerance. Preference or nonpreference is referred to as the group of plant characters and insect responses that lead the insect to or away from a particular plant or variety. Plant characters such as color, texture, taste, etc., might be involved in this type of resistance. Antibiosis involves the adverse effects on the life cycle of the insect feeding on the resistant plant or variety. These effects might include decreased size and fecundity, abnormal length of life, and increased mortality, especially in the early stages of development. Tolerance is considered to be the ability of the resistant plant to grow favorably in spite of supporting an infestation comparable to that damaging a susceptible host.

All three of these main categories of resistance appear to be present in plants resistant to the spotted alfalfa aphid (Howe and Smith, 1957). Antibiosis is especially obvious on highly resistant plants. Howe and Smith (1957) observed that young born on resistant parent plants of the variety Lahontan were restless and tended to scatter over the leaflets, and that many of these died in the early instars. McMurtry and Stanford (1960) noted that aphids confined to a highly resistant parent plant of Lahontan produced little honeydew and usually died within a period of 24-72 hours. Nielson and Curie (1959) studied the biology of the spotted alfalfa aphid on resistant and susceptible varieties. They observed such effects as increased length of nymphal period and nymphal mortality, and decreased adult survival and reproduction on the resistant varieties.

Observations by Howe and Smith (1957) and various sources of unpublished information have indicated that under certain conditions aphids may survive and reproduce on plants previously observed to be resistant. This suggested that the environment may have a profound effect on the expression of resistance. It is known that the environment may have a controlling effect on the expression of many genetic characters, hence it might be expected that a plant could exhibit a varying degree of resistance (or susceptibility) under different environmental conditions. This has been pointed out by Painter (1954), who cited various examples of this phenomenon.

With the above-mentioned factors in mind, the studies reported herein were carried out to determine the major environmental factors which might be responsible for altering the expression of host-plant resistance to the spotted alfalfa aphid. It is hoped that the results obtained will not only add to our knowledge of why plants apparently resistant to the aphid appear susceptible under certain conditions, but also will provide information leading to future studies on the basic nature of the resistance in these plants. 


\section{METHODS AND MATERIALS}

The expression of host resistance under various environmental conditions was determined by means of antibiosis tests in which a given number of apterous adult female spotted alfalfa aphids were confined to both resistant and susceptible plants. After various intervals of time, the number of remaining live adults and resulting live young on these plants was determined. By comparing the numbers of live aphids on resistant plants with those on the susceptible plants, the relative degree of resistance being expressed could be determined.

The spotted alfalfa aphids used in these studies were taken from a colony reared on potted plants in the greenhouse. Caliverde, a highly susceptible variety, was used for rearing purposes. The plant material used in the experimental work originated from vegetative cuttings of single plants, thus individual clones rather than varieties were used. This tended to reduce the variability between plant replications, as all plants of the same clone would have the same genetic make-up and should possess the same degree of aphid resistance if grown under exactly the same conditions. Therefore, any difference in expression of resistance between plants of the same clone would be expected to be due to environmental modifications rather than inherent differences. In contrast, a group of plants grown from seed of any resistant variety would probably not be homogenous in regard to resistance, and consequently this would be an undesirable source of variability in the experiments. In most of the experiments two resistant clones were compared with a susceptible clone. The resistant clones were two Lahontan parents designated as C-84 and C-902. Howe and Smith (1957) tested the aphid resistance of the parental clones of Lahontan and classified C-84 as highly resistant and C-902 as intermediate in resistance to the spotted alfalfa aphid. The susceptible clone was from the variety Caliverde.

Two types of cages were used for confining aphids to the plants. The first type used is shown in figure 1. Sections of transparent plastic sheeting were glued around galvanized metal ring supports, forming a cylinder 5 inches long and $3 \frac{1}{2}$ inches in diameter. A nylon sleeve was secured to the bottom end of the cylinder by means of a rubber band. A removable lid, consisting of a plastic ring covered with nylon cloth, closed off the top end. The cage was placed over a single alfalfa terminal and attached with rubber bands to two stakes inserted in the soil. Plugging cotton was placed around the lower part of the stem, and the sleeve was tied at this point to prevent escape of aphids. With the aid of a camel's-hair brush, test aphids were introduced onto leaflets through the top of the cage. This was facilitated by lowering the cage temporarily so that the upper leaves of the terminal extended out of the top. Satisfactory results were obtained with this type of cage. One disadvantage, however, was the time-consuming process of placing aphids directly on the leaflets and the associated difficulty caused by occasional individuals falling from the leaflets into the sleeve at the bottom of the cage during this operation. For this reason the cages were not used in all of the experiments.

The other type of cage employed is shown in figure 2 . These cages were made from plastic vials $1 \frac{1}{4}$ inches in diameter cut into $1 \frac{1}{2}$-inch cylinders. 


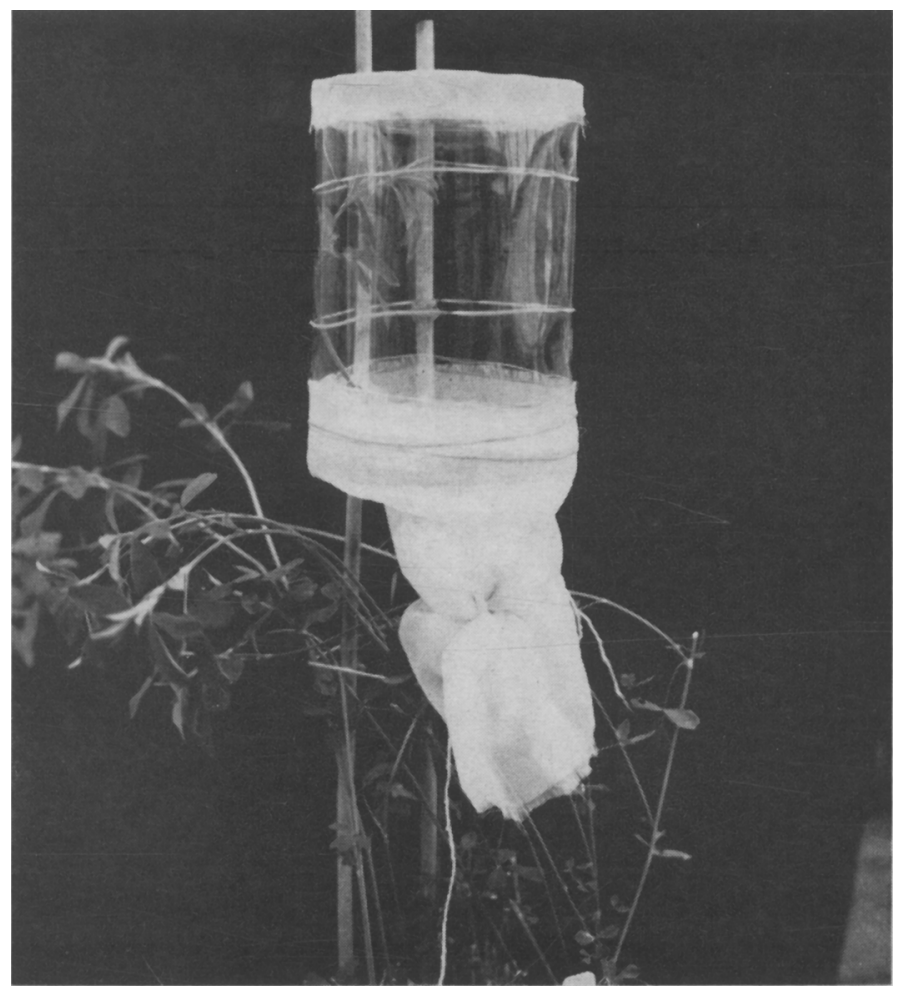

Fig. 1. Cage confining an alfalfa terminal.

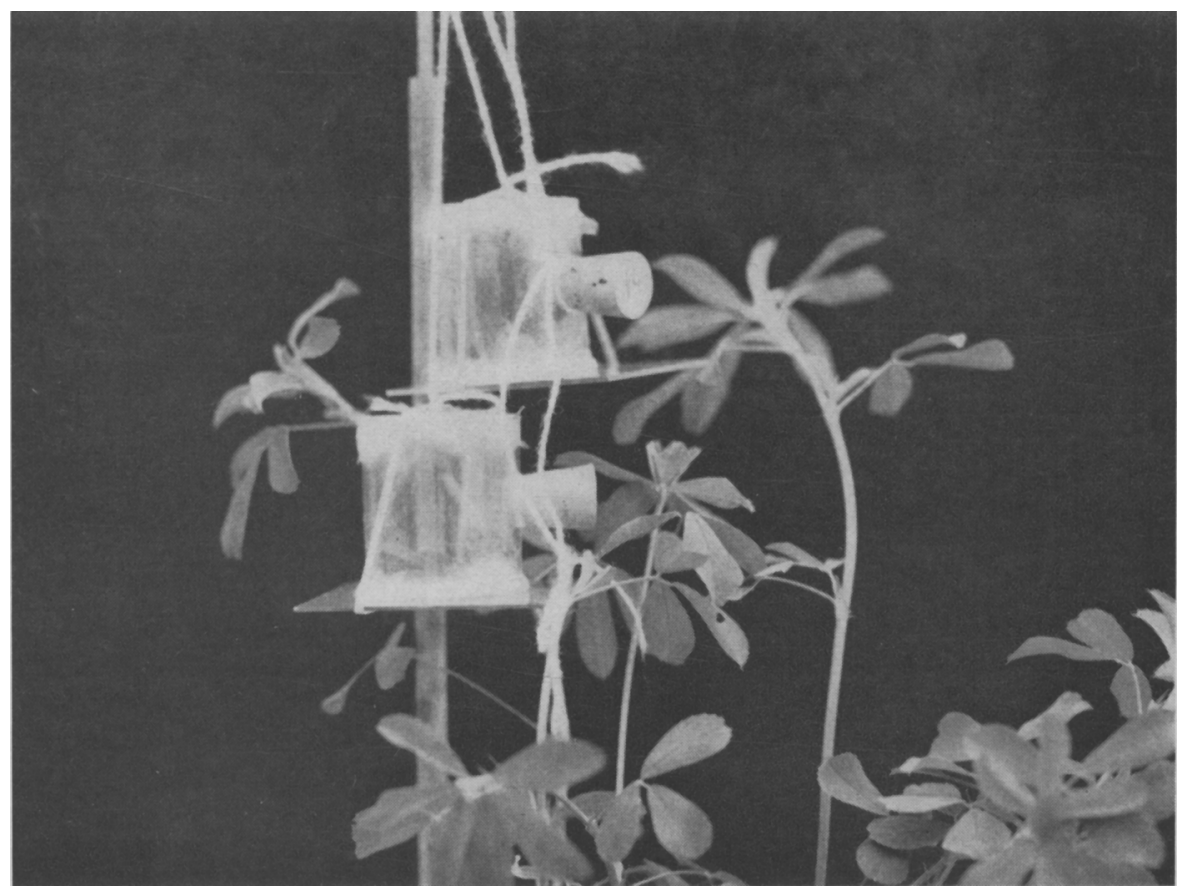

Fig. 2. Cage confining a single alfalfa trifoliate leaf. 
The top of the cylinder was covered with nylon stocking material, and a section of pipe cleaner was glued around the bottom edge. The bottom end of the cylinder was closed off by a $2 \times 2$-inch glass plate held in position by a rubber band. Single leaves were caged by inserting the petiole between the bottom edge of the cylinder and the glass plate. The pipe cleaner served to protect the petioles from injury by the cage and at the same time provided a tight seal to prevent escape of aphids. The cage was suspended by a string attached to a stake inserted in the soil. Adult aphids were dropped into the cage through a small hole in the side. With this type of cage it was found unnecessary to place aphids directly on the leaflets. This saving of time led to the adoption of this cage for the majority of the experiments. Another advantage was in the ease of counting contained aphids, since it was possible to see through any portion of the eage. The main disadvantage was that in confining a single leaf aphids were not free to feed on the stems, which on resistant plants apparently were preferred over leaves under some conditions. Thus, in using these cages, there may have been a tendency for the observed degree of resistance of plants to be slightly higher than when using larger cages where aphids had access to stems as well as leaves. However, this was not considered to be of serious consequence in experiments where the main interest was in an evaluation of relative degrees of resistance.

\section{RESISTANCE IN RELATION TO TEMPERATURE}

Since temperature is known to affect numerous physiological processes in plants and animals, it is not surprising that it should also affect the expression of resistance of plants to insects. Dahms and Painter (1940) showed that the pea aphid, Macrosiphum pisi (Harris), had a higher reproductive capacity on resistant plants at low temperatures. Cartwright et al. (1946) found that Hessian fly resistance in certain varieties of wheat became less pronounced at high temperatures. Howe and Smith (1957) noted that under cool fall weather conditions, spotted alfalfa aphids could complete development on resistant plants on which they were unable to survive during the summer months. It was observed by the writer (unpublished data) that highly resistant plants appeared to be at least partially susceptible when tested for resistance during the cool season of the year. Thus, there were indications that temperature may be an important factor affecting the expression of host-plant resistance to this aphid. Studies independent of those reported in this paper were carried out by Hackerott and Harvey (1959). These authors were the first to demonstrate effects of temperature on hostplant resistance to the spotted alfalfa aphid.

\section{Resistance at Various Constant Temperatures}

It appeared that a laboratory study under controlled temperature conditions could establish whether or not temperature was the major factor in altering the expression of spotted alfalfa aphid resistance during certain times of the year. Such a study could also provide sufficient data to formulate a resistance curve in relation to temperature, thus showing whether the aphid resistance of a given plant might change gradually over a wide temperature range, or conversely, whether it might change sharply beyond a certain 
critical temperature. It seemed that such information might lead to a better understanding of the mechanism of resistance.

Procedure. Aphid survival and reproduction was observed on resistant and susceptible plants at six different temperatures- $85^{\circ}, 76^{\circ}, 71^{\circ}, 68^{\circ}, 60^{\circ}$, and $50^{\circ} \mathrm{F}$. With the exception of the $50^{\circ} \mathrm{F}$ test, studies were carried out in plant growth chambers in the Department of Agronomy, University of California, Davis; the source of the $50^{\circ} \mathrm{F}$ temperature was a refrigerated room in the Entomology Department Insectary. Temperatures remained constant within $\pm 2^{\circ} \mathrm{F}$. Lighting was produced by fluorescent tubes supplemented by tungsten filament bulbs. A photoperiod of 16 hours was maintained. Since it was not possible to control humidity, there was generally an increased humidity with decreasing temperatures. The values ranged from 40 to $55 \%$ at $85^{\circ} \mathrm{F}$ to 75 to $95 \%$ at $50^{\circ} \mathrm{F}$.

TABLE 1

EFFECT OF DIFFERENT CONSTANT TEMPERATURES ON APHID SURVIVAL AND REPRODUCTION ON RESISTANT AND SUSCEPTIBLE

ALFALFA CLONES*

\begin{tabular}{|c|c|c|c|c|c|c|}
\hline \multirow{2}{*}{ Temperature ${ }^{\circ} \mathrm{F}$} & \multicolumn{2}{|c|}{ C-84 (Highly resistant) } & \multicolumn{2}{|c|}{ C-902 (Intermediate) } & \multicolumn{2}{|c|}{ Caliverde (Susceptible) } \\
\hline & Live adults & Live young & Live adults & Live young & Live adults & Live young \\
\hline $85 \ldots$ & 0.0 & 0.0 & 0.7 & 19.0 & 9.7 & 261 \\
\hline 76. & 0.0 & 0.0 & 2.0 & 29.0 & 8.5 & 248 \\
\hline $71 .$. & 0.0 & 3.3 & 5.7 & 121.0 & 9.7 & 221 \\
\hline 68. & 0.0 & 2.3 & 8.3 & 96.0 & 9.7 & 146 \\
\hline 60 . & 6.7 & 28.0 & 9.7 & 77.0 & 8.0 & 66 \\
\hline $50 \ldots \ldots$ & 8.7 & 31.0 & 10.0 & 53.0 & 10.0 & 59 \\
\hline
\end{tabular}

* Based on live aphids per replication five days after adult females were placed on the plants. Began test with 10 adult females per replication.

Test plants, which were grown previously in the greenhouse, were placed in the controlled temperature rooms six days prior to introduction of aphids. Clones C-84, C-902, and a Caliverde check were used, each clone being replicated three times at each temperature. All plants used were in a state of vigorous growth.

A single terminal on each plant was caged with one of the cylindrical cages previously described (fig. 1). The caged portion of the terminal contained four to six trifoliate leaves. Ten apterous adult females were placed on each caged terminal (one replication), resulting in a total of 30 adults per clone. Daily counts of live adults and cumulative live progeny were carried out for at least five days. At $76^{\circ}$ and $85^{\circ} \mathrm{F}$, counts on susceptible Caliverde plants were terminated after five days, as high reproduction rates caused considerable crowding of aphids by this time. This made counting difficult and probably produced conditions unfavorable to normal reproduction. At the lower temperatures, counts were made for at least six days. Counting at the $50^{\circ} \mathrm{F}$ test was extended to 14 days, since it was considered possible that the low rate of metabolism of the aphids at this temperature might be responsible for a slow reaction to resistance in the host plants. Observations for any characteristic appearance or behavior patterns of aphids were also made.

Results. Average counts of live adults and young five days after adults 
were placed on the plants are shown in table 1 for each of the constant temperatures tested. An analysis of variance of the data was performed by treating the total experiment as a split plot design, using temperatures as the main units and alfalfa clones as the subunits. Total live aphids after five days were transformed to $\log (x+1)$ for the analysis. Differences in aphid numbers between temperatures, between clones, and the interaction of clones $x$ temperatures were all found to be significant at the $1 \%$ level of probability. It is evident from table 1 that temperature and clone both had a profound effect on aphid population build-up, and also that temperature affected aphid build-up to a different degree on each of the three clones.

On Caliverde plants, there was little mortality of aphids at any of the temperatures. It is evident that reproduction of the adult aphids was considerably higher at high than at low temperatures.

Clone C-84 was completely immune to spotted alfalfa aphid infestation at $76^{\circ}$ and $85^{\circ} \mathrm{F}$, as no aphids survived as long as 48 hours after introduction of the original aphids on to the plants. Some young were produced but none survived. No droplets of honeydew could be observed on the sides of the cages, suggesting that the aphids had done little or no feeding. In contrast, aphids on the Caliverde plants deposited profuse amounts of honeydew on the sides of the cages.

Clone C-902, considered to be intermediate in resistance (Howe and Smith, 1957), appeared quite highly resistant at both $85^{\circ}$ and $76^{\circ} \mathrm{F}$. Daily counts showed that a steady decline in total live aphids occurred after the first day at $85^{\circ} \mathrm{F}$, while a very slight increase in numbers occurred throughout the test at $76^{\circ} \mathrm{F}$.

Thus, it is seen that both C-84 and C-902 were very unfavorable for aphid development at $76^{\circ}$ and $85^{\circ} \mathrm{F}$. It was noted that the adult aphids became shrunken in appearance, as if in a desiccated condition. Many were observed to be rapidly crawling around on the plants. Those which settled down tended to aggregate on the stems and petioles, while aphids on susceptible Caliverde plants preferred the undersides of the leaflets. Similar behavior of the aphids on resistant plants was reported by Howe and Smith (1957). Many dead early instar nymphs were observed at the bottom of the cages on both resistant clones at $76^{\circ}$ and $85^{\circ} \mathrm{F}$. Thus the actual production of young was higher than indicated in table 1, as those values represent only living young on the plants.

At $71^{\circ} \mathrm{F}$ it appeared that $\mathrm{C}-84$ plants may not have been quite so highly immune as at $85^{\circ}$ and $76^{\circ} \mathrm{F}$, since a few live young still remained on the plants at the sixth day of the test. It appeared doubtful, however, that any of these young would have been able to develop to maturity, since a high mortality rate was observed.

C-902 plants were considerably more favorable to aphid colonization at $71^{\circ} \mathrm{F}$ than at the two higher temperatures, as can be seen in table 1 . As observed at the higher temperatures, the adult aphids aggregated mainly on the stems and petioles rather than on the leaves. On this basis it was not difficult to distinguish C-902 from Caliverde.

Some of the surviving adults on the C-902 plants at $71^{\circ} \mathrm{F}$ were somewhat smaller or more shrunken than they were when first introduced, but most 
appeared normal in this respect. Thus, at $71^{\circ} \mathrm{F}$ some adults died but others were able to survive and apparently feed and reproduce quite readily. Little restlessness of aphids was observed on this clone at $71^{\circ} \mathrm{F}$ compared with that which occurred at the higher temperatures. At this temperature, C-902 exhibited a degree of resistance that might be expected of a plant classed as intermediate in resistance, whereas at higher temperatures it appeared to be highly resistant.

At $68^{\circ} \mathrm{F}$ the number of aphids present on C-902 relative to Caliverde was greater than at $71^{\circ} \mathrm{F}$, although lower in absolute numbers. Adult mortality was also lower at $68^{\circ} \mathrm{F}$. At this temperature most adult aphids on C-902 were feeding on the leaves rather than on the stems as at the higher temperatures. Stem feeding - a seemingly characteristic aspect of behavior of the aphids on resistant plants - thus was not evident on C-902 at this lower temperature. Instead, most aphids in this respect behaved like those feeding on Caliverde plants.

At $60^{\circ} \mathrm{F}, \mathrm{C}-84$ appeared to be considerably more susceptible than at higher temperatures since at the final count, eight days later, some adults were still surviving and reproducing, and some of the progeny had reached the second and third instars. Numerous honeydew droplets were observed, indicating that feeding had taken place, but the presence of many dead young showed that C-84 was still quite unfavorable. Daily counts showed that the population was barely maintaining a constant level. However, it appeared that some of the young might have developed to maturity, although the test was not carried out long enough to demonstrate this.

Clone C-902 gave no indication of resistance at $60^{\circ} \mathrm{F}$. All aspects of aphid behavior and appearance were apparently no different from that of aphids on Caliverde plants.

Results at $50^{\circ} \mathrm{F}$ indicated that clone C-84 became sufficiently favorable for aphid colonization. Counting was continued for 14 days, and the total aphid population was still increasing on C-84 at this time. Nearly all adult aphids were still alive at the end of 14 days. These adults settled on the stems, as at higher temperatures, which suggested that the leaves of C-84 were still unfavorable. Evidence of many dead nymphs also indicated resistance in the plants. Clone C-902 again showed no indication of resistance.

At the end of 14 days, all adult aphids were removed from the plants. The progeny were left undisturbed for an additional 16 days. This was carried out in order to determine whether aphids at $50^{\circ} \mathrm{F}$ could actually reach maturity and complete their life cycle on all three clones. At the end of this 16-day period, adults were observed on all clones, showing that some of the young born during the test had completed their development. Fewer adults were observed on C-84 than on the other two clones. No differences in size or general appearance of aphids maturing on the different clones were noted. These observations reveal that at $50^{\circ} \mathrm{F}$ the life cycle of at least some of the aphids can be completed on the two "resistant" clones.

The same plants with their aphid colonies were then transferred to warm temperatures in the greenhouse. Aphid counts, made several days after transfer to the greenhouse, indicated that C-84 again became immune and C-902 again showed some resistance, while Caliverde plants supported rapidly increasing populations of aphids. 


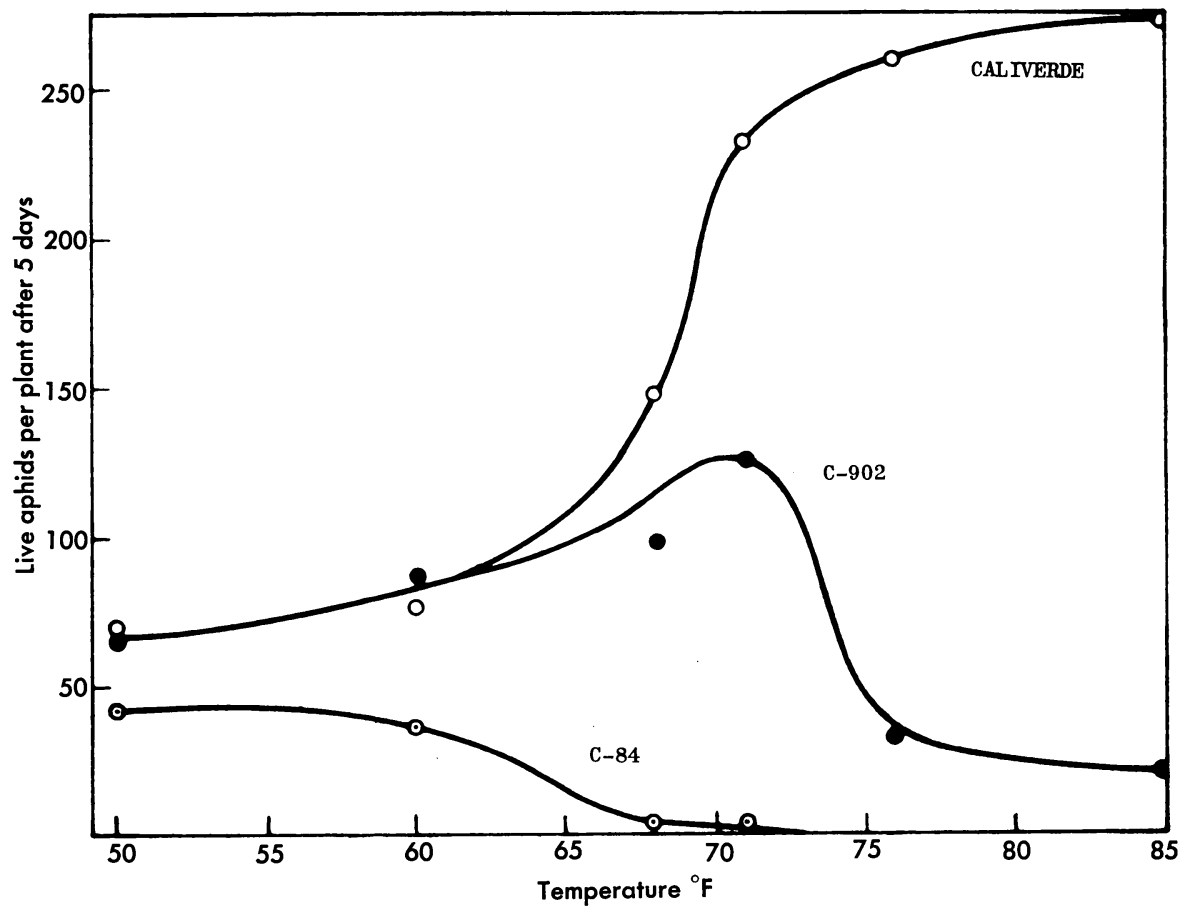

Fig. 3. Aphid population levels in relation to temperature.

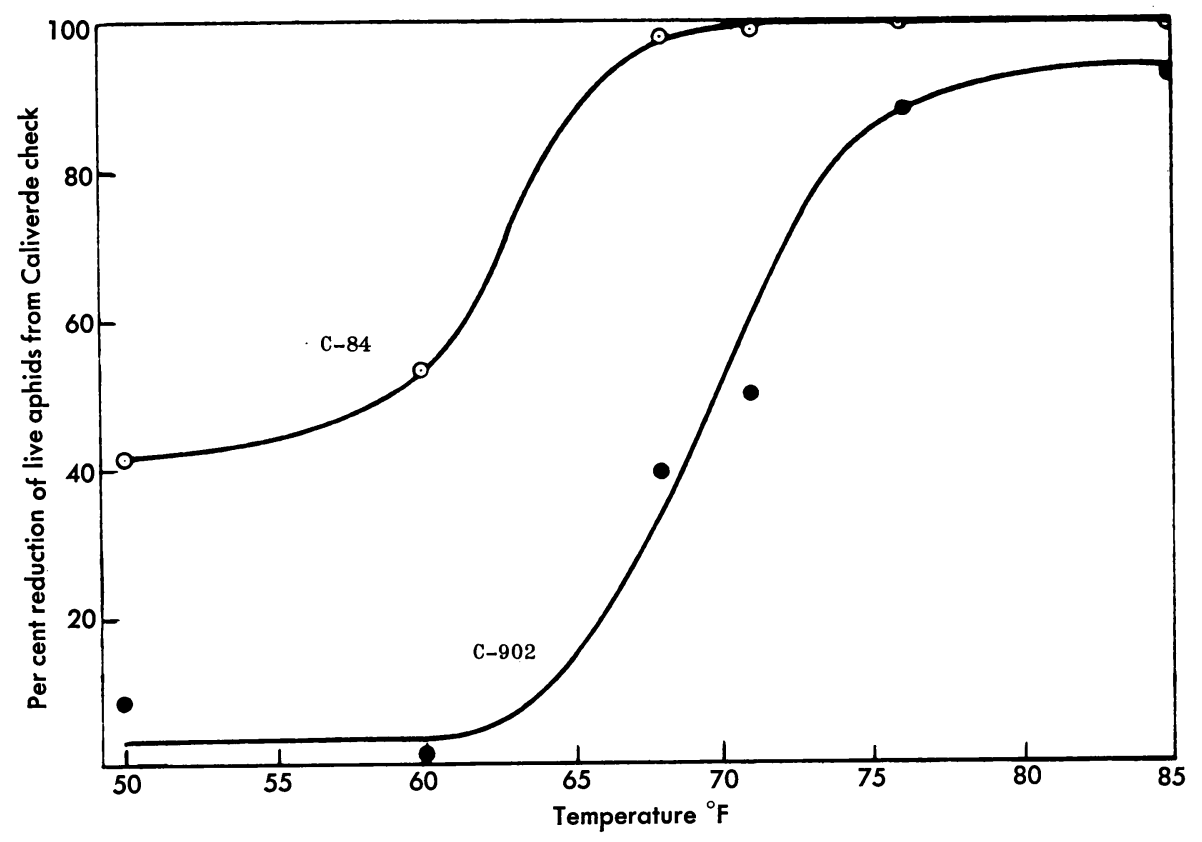

Fig. 4. Relative resistance of C-84 and C-902 in relation to temperature. 


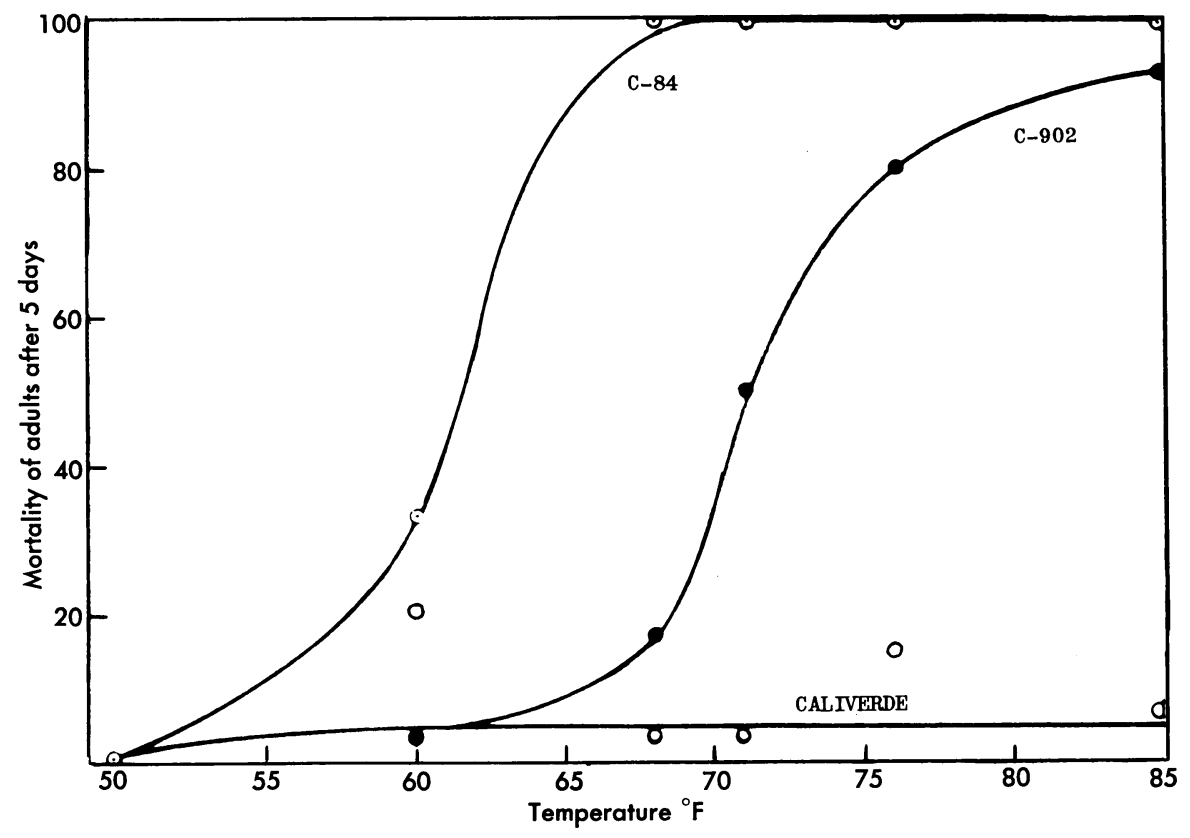

Fig. 5. Adult mortality in relation to temperature.

Discussion. An over-all view of the relationship of temperature to spotted alfalfa aphid infestation on resistant and susceptible clones is presented in figures 3, 4, and 5. Figure 3 shows the live aphids per plant (replicate) after five days, plotted against temperature. On Caliverde plants, a definite sigmoidal relationship is evident, showing the most rapid increase in number of aphids with a rise in temperature within a range of approximately $65^{\circ}$ to $71^{\circ} \mathrm{F}$. The number of aphids on the Caliverde plants at the end of five days was dependent on the rate of reproduction of the original adult females, as none of the young born during this time had reached maturity. The lower populations at the lower temperatures on Caliverde can be considered the result of low temperatures causing a slowing down of the reproductive process, rather than decrease in susceptibility of the host plant. Higher temperatures accelerated the reproductive rate, resulting in larger numbers of aphids in a given amount of time than occurred at low temperatures.

Harpaz (1955), Dickson, Laird, and Pesho (1955), and Graham (1959) have demonstrated that, within a certain temperature range, reproduction rate of the spotted alfalfa aphid on susceptible plants increases with rising temperatures. The most critical study was carried out by Graham, whose data indicated that the maximum fecundity rate occurred at $25^{\circ} \mathrm{C}\left(77^{\circ} \mathrm{F}\right)$ at low and intermediate humidities, but was considerably lower at $30^{\circ} \mathrm{C}$ $\left(86^{\circ} \mathrm{F}\right)$. This does not appear to be in agreement with the present studies, which indicated that fecundity rate on Caliverde at $85^{\circ} \mathrm{F}$ was as high as, or higher than, at $76^{\circ} \mathrm{F}$. However, Graham's data represented mainly the 
average fecundity rate over the entire reproductive period of the adults, while these data represent the rate for only a five-day period. It is quite possible that exposure of adult aphids to constant temperatures as high as $85^{\circ} \mathrm{F}$ might result in a high reproductive rate for short periods, which would later be followed by a decline in the rate of reproduction. Other factors, such as humidity differences, also may have been responsible for the discrepancies between Graham's data and those presented herein.

Figure 3 shows that the population level of aphids on clone C-902 increased with rising temperatures up to $71^{\circ} \mathrm{F}$, and thereafter decreased rapidly. It appears, therefore, that a temperature of approximately $71^{\circ} \mathrm{F}$ was a critical point for the expression of resistance in this clone. Above $71^{\circ} \mathrm{F}$, a further increase in temperature apparently produced an increase in resistance so that a considerably higher aphid mortality resulted. This factor thus offset the tendency of aphids to build up more rapidly with a further increase in temperature, as occurred on the susceptible Caliverde plants. Aphids on C-84 showed smaller populations with increasing temperatures, so that $50^{\circ} \mathrm{F}$ appeared to be the most favorable temperature within the range studied.

The build-up of the spotted alfalfa aphid on the resistant clones apparently was dependent on two major factors: (1) the tendency of the aphids' reproductive rate to increase with rising temperatures, and (2) the tendency of host resistance to increase with rising temperatures. These two factors acted antagonistically to each other, as can be observed in figure 3. In C-902 plants, (1) appears to be the dominant factor, up to $71^{\circ} \mathrm{F}$, since an increase in temperature produced a higher population level. However, beyond $71^{\circ} \mathrm{F}$ the increasing resistance in the plants became the controlling factor since increases in the temperature beyond this point resulted in progressively lower aphid populations. Thus, it might be said that there is a variable balance between processes (1) and (2), which is dependent on the temperature. In C-84, the resistance appeared to be the dominant factor within the entire range, since rise in temperature resulted only in a decrease in the population level.

Dahms and Painter (1940) indicated that the optimum temperature for pea aphid population increase was lower on resistant than on susceptible alfalfa plants. Applying this concept to the present studies, it would appear from figure 3 that the optimum temperature for spotted alfalfa aphid build-up on clone C-902 was approximately $71^{\circ} \mathrm{F}$, while that on C-84 was the lowest temperature at which testing was carried out. It then follows that the optimum temperature for population increase is lowest on the plants showing the highest degree of inherent resistance.

A direct measure of resistance of the resistant clones as compared with the susceptible Caliverde at each temperature is expressed in percentage reduction in figure $4 .^{5} \mathrm{It}$ is shown that aphid populations at $50^{\circ}$ and $60^{\circ} \mathrm{F}$ on C-902 were essentially as large as on Caliverde, indicating that there was no resistance in C-902 within this range of temperatures. Beyond $60^{\circ}$ to $65^{\circ} \mathrm{F}$, however, a rapid increase in the expression of resistance is shown. A temper-

$$
\text { "Percent reduction }=\frac{\begin{array}{c}
\text { aphids per plant } \\
\text { on Caliverde }
\end{array}-\begin{array}{c}
\text { aphids per plant on } \\
\text { resistant clone }
\end{array}}{\text { aphids per plant on Caliverde }} \times 100 \text {. }
$$


ature of $60^{\circ}$ to $65^{\circ} \mathrm{F}$ thus appears to be the threshold for the expression of resistance in C-902. C-84 exhibited an intermediate level of resistance at $50^{\circ} \mathrm{F}$ and became nearly immune at $68^{\circ} \mathrm{F}$. It appeared that the sigmoidaltype curves as drawn in figure 4 best represent this relationship. It is interesting to note that the two curves roughly parallel each other. This might suggest that aphid resistance in the two clones is of the same nature, the difference in resistance being only a matter of degree. Therefore, a lowering of temperature may act in the same way in reducing the expression of resistance in both clones, except that a lower temperature is necessary in C-84 than in C-902.

Adult mortality curves appear in figure 5. Adults on Caliverde plants show no consistent differences in mortality at high or low temperatures, the values being very low except at $60^{\circ}$ and $76^{\circ} \mathrm{F}$. The higher mortality at these two temperatures probably can be attributed to experimental error, and it seemed justifiable to draw the line as shown. Clone C-902 produced no mortality of adults at temperatures below $68^{\circ} \mathrm{F}$. From this point, a rapid increase in mortality occurred with increasing temperatures, indicating that the expression of resistance to adult aphids changed from a low level to a high level within a range of less than $10^{\circ} \mathrm{F}\left(68^{\circ}\right.$ to $\left.76^{\circ} \mathrm{F}\right)$. Clone C-84 likewise caused no adult mortality after five days at $50^{\circ} \mathrm{F}$. Above $50^{\circ} \mathrm{F}$, however, mortality increased rapidly and reached 100 per cent at $68^{\circ} \mathrm{F}$. In terms of this adult mortality, C-84 would appear to be susceptible at $50^{\circ} \mathrm{F}$. In terms of total live aphids, however, resistance of at least an intermediate level was indicated. This suggests that comparative production and survival of young is a more critical measure of resistance than adult mortality. This is in agreement with Hackerott and Harvey (1959).

The results of this series of experiments demonstrate that low temperatures resulted in a decrease in the expression of spotted alfalfa aphid resistance in both a highly resistant and a partially resistant clone of alfalfa. Hackerott and Harvey (1959), in studying resistance of two selections from the variety Buffalo, one intermediate and one resistant, also demonstrated that aphids tend to survive and reproduce better on resistant plants at low temperatures. These workers found that the resistant and intermediate clones could be distinguished from the susceptible clone at all temperatures studied, the lowest being $60^{\circ} \mathrm{F}$. This differs from the results here reported in that the intermediate clone C-902 could not be distinguished from the susceptible clone in regard to aphid populations at $50^{\circ}$ and $60^{\circ} \mathrm{F}$. By the procedures employed, both clones appeared susceptible at these temperatures. It appears that the intermediate clone used by Hackerott and Harvey exhibited a higher degree of inherent resistance than clone C-902 used in these studies. Thus, by using a somewhat more susceptible clone, it is demonstrated that some plants classed as intermediate in resistance apparently can become completely susceptible under certain conditions.

Examination of figures 4 and 5 indicates that there may be a critical temperature range in which a change in the temperature markedly affects the expression of resistance. This critical range was apparently about $60^{\circ}$ to $68^{\circ} \mathrm{F}$ for $\mathrm{C}-84$ and approximately $65^{\circ}$ to $75^{\circ} \mathrm{F}$ for C-902. Apparently, then, the temperature range where resistance changed rapidly was fairly narrow 
$\left(8^{\circ}\right.$ to $\left.10^{\circ} \mathrm{F}\right)$. This implies that relatively small changes in temperature could markedly affect the resistance of certain plants. Since plants within resistant varieties of alfalfa will vary in their inherent resistance, it is evident that certain changes in the temperature might greatly affect the resistance of some plants, while only slightly or not at all affecting others. For example, a change from $70^{\circ}$ to $80^{\circ} \mathrm{F}$ was shown to greatly alter the expression of resistance in C-902 but not in C-84 (fig. 4 ).

The inconsistent results sometimes obtained in testing plants for resistance to the spotted alfalfa aphid might well be explained at least in part on the basis that the plants were tested under somewhat different temperature conditions. Consequently, it becomes necessary to include temperature records when presenting data indicating resistance in certain varieties or clones of alfalfa.

From the economic standpoint, the tendency of aphids to survive better on resistant plants at low temperatures would not be expected to be of serious consequence, since at low temperatures spotted alfalfa aphid populations build up relatively slowly and usually do not reach outbreak proportions. At higher temperatures, when populations have greater tendency to reach economic levels, resistance would be expressed to a higher degree, making the resistant plants unfavorable for rapid increase in the aphid populations.

A loss of resistance to the spotted alfalfa aphid at low temperatures conceivably could be of economic significance if aphids became adjusted to the resistant plants in such a way that when warm weather returned they could better survive on these plants. In other words, could aphids which fed on resistant plants at low temperatures become conditioned to these plants so that they could also survive and reproduce well on the same plants at high temperatures? This does not appear likely, as aphids reproducing on resistant clones at $50^{\circ} \mathrm{F}$ showed a high mortality when the plants were again returned to high temperatures.

\section{Change in Resistance as Affected by a Change in Temperature}

Differences in the expression of resistance in C-84 and C-902 plants under different temperatures were demonstrated in the previous section. To gain additional information about the nature of this process, it seemed desirable to determine the length of time necessary for this change in resistance to take place when the plants were moved from a high to low, or low to high, temperature. In the previous tests, all plants were conditioned at the constant temperatures at which they were tested for a period of six days before aphids were placed on them. This amount of time apparently was sufficient for any change in the resistance to become complete. It had not been shown, however, whether the change in expression of resistance occurred almost immediately upon exposure of the plants to a new temperature, or whether this required several days to be completed. The series of experiments described in this section were devised in order to determine the approximate time interval necessary for resistance to be lost or regained when moving resistant plants from one temperature to another.

It was not known whether the effect of temperature on expression of resistance was due primarily to a response of the aphids or the plants 
(Hackerott and Harvey, 1959). Temperature may in some way affect the aphids directly so that they are better able to survive on resistant plants at low temperatures. On the other hand, temperature may affect certain physiological or other processes of the plant itself so that it becomes more favorable for aphid feeding and survival at low temperatures. There have been certain indications in the course of this study that the latter possibility is involved. The results of the experiments in this section also tend to support these indications.

Procedure. In devising experiments to determine the length of time required for resistance to become altered by a change in temperature, it was tentatively assumed that this altering of resistance was due to a change in the plant rather than in the aphid. The two resistant clones were studied separately. Essentially, the procedure was to measure aphid survival and reproduction on resistant plants that had been exposed to a new temperature for varying periods of time. To study the amount of time required for a loss of resistance to occur when transferring plants from a high to a low temperature, several individual plants that had been growing at warm temperatures were transferred to a cold-temperature room on different days within a 1-week period. After the last plant was introduced into the cold-temperature room, aphids were placed on all of the transferred plants. Thus, one group of aphids was placed on a plant that had been exposed to the low temperature for less than 1 hour (referred to as 0 days in the data). Another group of aphids was confined to a plant that had been exposed to this temperature for 1 day. In like manner, other groups of aphids were introduced on plants that had been at the low temperature for 2, 3, 5, and 7 days in tests with C-84 plants, and for 2,4 , and 6 days in tests with C-902 plants.

To investigate the amount of time required for resistance to be regained upon moving plants from cold to warm temperatures, the procedure was conducted in reverse. In this ease, all plants transferred to warm temperatures had been held at the cold temperature for a period of 6 days.

The source of the cold temperature was the $50^{\circ} \mathrm{F}$ room used previously, and the source of the warm temperature was, in most cases, a greenhouse having a temperature range of $70^{\circ}$ to $80^{\circ} \mathrm{F}$. In one individual test, the source of the warm temperature was a plant-growth chamber held at $95^{\circ} \mathrm{F}$. The small leaf cages previously described were employed in these experiments. In the C-84 tests 10 adult apterae were placed in each of 3 cages containing a trifoliate leaf, resulting in 30 adults on each plant. In the C-902 tests, only 6 adults were introduced into each of 5 cages (also 30 per plant) since higher reproduction and the possibility of crowding was anticipated. Counts of live adults and cumulative live progeny were made at daily intervals. Where it seemed desirable, Caliverde check plants were provided and comparable numbers of adult aphids were introduced.

The time required for resistance of the plants to be lost or regained could not be determined with complete accuracy by this method, since the reaction of the aphids to plant resistance (in the form of mortality) was not immediate. A pronounced aphid mortality on resistant plants did not occur until after about 48 hours at high temperatures and even longer periods at low temperatures. Thus, if aphids were confined on a plant that had been exposed 
to a new temperature for less than 1 hour, for example, the degree of resistance of this plant could not be accurately determined until after about 48 hours. The plant during this 48 -hour period could have been progressively changing in resistance, so that nymphs born the second day might have encountered different feeding conditions than those born the first day. It is necessary to keep this factor in mind in interpreting final results.

The time required for loss of resistance to occur in C-902 plants transferred from high to low temperatures was further investigated using a different technique, since results obtained with C-902 by the above-described procedure were inconclusive. This technique involved the use of first-instar nymphs, since they had been found to be a very sensitive index of plant resistance. The test plants were grown at a constant temperature of $95^{\circ} \mathrm{F}$ for 6 days, insuring a sufficiently warm temperature for expression of resistance before the plants were transferred to the low temperature. Testing for resistance involved placing the nymphs on trifoliate leaves of excised stems (cuttings). The stems were placed in vials of water and were held in place by a wad of cotton. This excised-stem technique facilitated counting and transferring of the small nymphs. Thus the excised stems rather than the whole plants were transferred from the warm to the cold temperature. Four stems were used for each treatment, with ten first-instar nymphs being introduced on the leaf of each stem.

In the first treatment, stems taken from plants held at $95^{\circ} \mathrm{F}$ were placed in the $50^{\circ} \mathrm{F}$ room and aphids immediately placed on the leaflets. After 48 hours, aphids still remaining on the cuttings were counted and then transferred to fresh cuttings just brought in from the $95^{\circ} \mathrm{F}$ room. This procedure was repeated every 48 hours for a period of eight days. Thus, aphids in this treatment were at all times on excised stems that had been exposed to the $50^{\circ}$ F temperature for $0-48$ hours. With this method, all nymphs of a given treatment were exposed to the same feeding conditions in the plant.

In the second treatment, excised stems were taken from plants in the $95^{\circ} \mathrm{F}$ room and allowed to remain at $50^{\circ} \mathrm{F}$ for 24 hours before the aphids were placed on them. After an additional 48 hours the aphids still remaining were transferred to fresh cuttings similarly held at $50^{\circ} \mathrm{F}$ for 24 hours. The procedure was carried out for 8 days as before. Therefore, in this treatment, aphids were on cuttings that had been exposed to $50^{\circ} \mathrm{F}$ for 24 to 72 hours. In a third treatment, excised stems of plants held at $95^{\circ} \mathrm{F}$ were transferred to $50^{\circ} \mathrm{F}$ and allowed to remain for 48 hours before aphids were introduced. This group of aphids thus was on stems exposed to $50^{\circ} \mathrm{F}$ for 48 to 96 hours. In another treatment, the same procedure was followed using stems of plants subjected to $50^{\circ} \mathrm{F}$ for a period of 6 days.

Tests with Clone C-84. Table 2 shows aphid counts on C-84 plants moved from warm to cold temperatures. No consistent differences in live adult aphids could be observed between plants kept at $50^{\circ} \mathrm{F}$ for different periods of time. However, in the case of live young, a definite trend appeared in 72 hours. The data show that in general, plants held at $50^{\circ} \mathrm{F}$ for the longest periods of time supported the highest numbers of live young. A chi-square analysis indicated that the plants differed significantly in their degree of resistance, depending on the time of exposure to the cold temperature $\left(x^{2}=\right.$ $16.71, \mathrm{P}=<.01)$. 
TABLE 2

PERIODIC APHID COUNTS ON C-84 PLANTS EXPOSED TO COLD TEMPERATURES FOR DIFFERENT TIME INTERVALS*

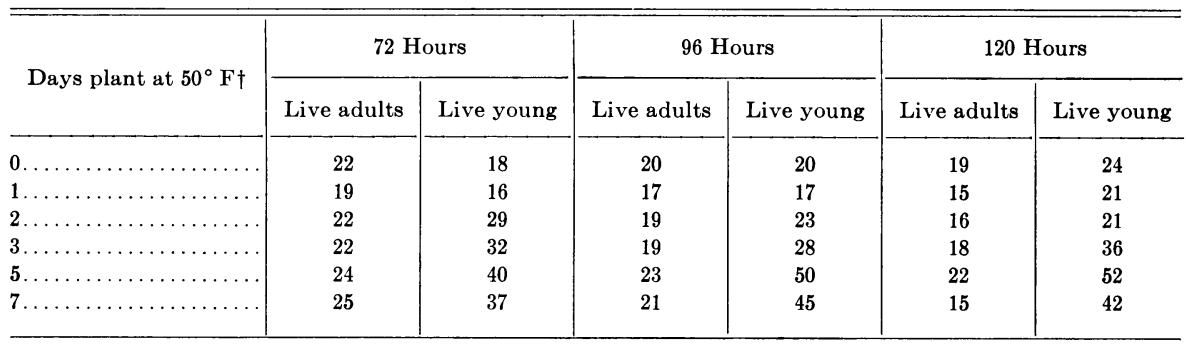

* Began tests with 30 adults per plant.

$\dagger$ Days at $50^{\circ} \mathrm{F}$ at the time adult aphids introduced.

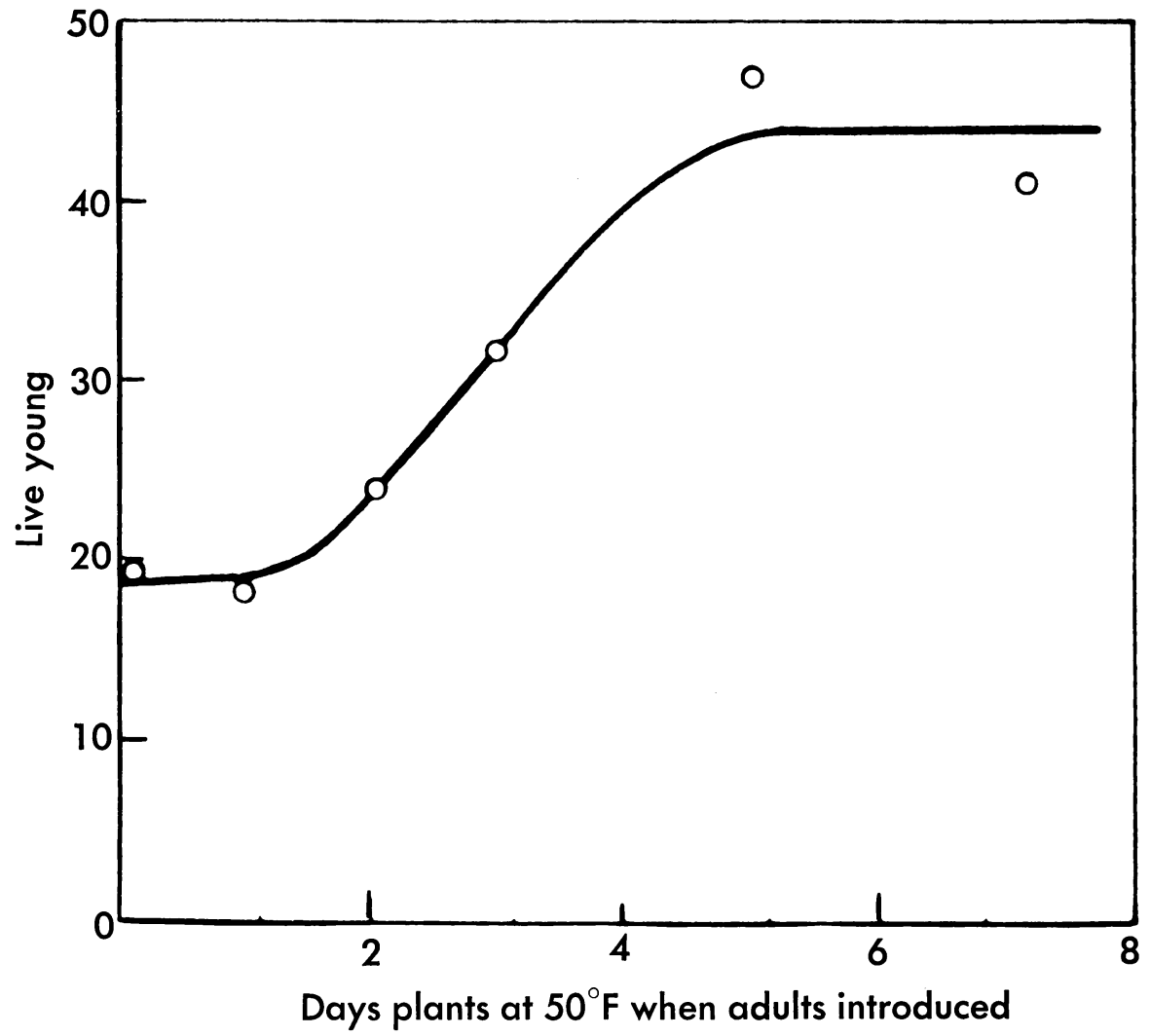

Fig. 6. Resistance of C-84 in relation to time exposed to low temperatures. 
Figure 6 illustrates this relationship. The numbers of live young shown are averages of the 72,96 , and 120 -hour counts. Since there were comparatively small numbers of young involved and a rather inconsistent day-to-day change in numbers on a given plant, it seemed that the average of several counts would be more reliable for presentation. Figure 6 indicates that C-84, when moved from warm to cold temperatures, lost resistance with increasing time. Approximately 5 days at $50^{\circ} \mathrm{F}$ appeared to be sufficient for the change in expression of resistance to become complete.

TABLE 3

PERIODIC APHID COUNTS ON C-84 PLANTS EXPOSED TO WARM TEMPERATURES FOR DIFFEREN'T TIME INTERVALS*

\begin{tabular}{|c|c|c|c|c|c|c|}
\hline \multirow{2}{*}{ Days plant out of $50^{\circ} \mathrm{F} \dagger$} & \multicolumn{2}{|c|}{24 Hours } & \multicolumn{2}{|c|}{48 Hours } & \multicolumn{2}{|c|}{72 Hours } \\
\hline & Live adults & Live young & Live adults & Live young & Live adults & Live young \\
\hline $0 \ldots \ldots \ldots \ldots \ldots \ldots \ldots \ldots$ & 29 & 99 & 27 & 130 & 25 & 144 \\
\hline $1 \ldots \ldots \ldots \ldots \ldots \ldots \ldots$ & 29 & 75 & 20 & 73 & 16 & 48 \\
\hline $2 \ldots \ldots \ldots \ldots \ldots$ & 24 & 46 & 16 & 25 & 13 & 24 \\
\hline $3 \ldots$ & 27 & 59 & 19 & 32 & 11 & 17 \\
\hline $5 \ldots \ldots \ldots$ & 25 & 57 & 17 & 36 & 8 & 20 \\
\hline $7 \ldots \ldots \ldots \ldots \ldots \ldots \ldots \ldots$ & 22 & 47 & 9 & 19 & 3 & 7 \\
\hline
\end{tabular}

* Began tests with 30 adults per plant.

$\dagger$ Days out of the $50^{\circ} \mathrm{F}$ room at the time adult aphids introduced.

Table 3 shows aphid counts on C-84 plants moved from cold to warm temperatures. A general trend, again more pronounced in the young, was evident at the first count and was still more distinct at the 48- and 72-hour counts. It is seen that considerably higher numbers of live aphids were present on the plants that had been out of the $50^{\circ} \mathrm{F}$ room for the two shortest periods of time; this suggests that these plants still maintained some of the susceptibility which they possessed at $50^{\circ} \mathrm{F}$. A chi-square analysis of live young at 24 hours indicated that there were significant differences between plants $\left(\chi^{2}=21.68, \mathrm{P}=<.01\right)$. Thus, it is inferred that the degree of resistance of C-84 varied according to the interval of time the plants had been out of the low temperature room. Figure 7 illustrates this relationship. In observing this graph, it would seem that two days' exposure to warm temperatures previous to infesting with aphids was sufficient time for clone C-84 to gain its maximum level of resistance under the existing conditions.

Tests with Clone C-902. Results of the test devised to determine the period of time necessary for C-902 plants to lose their expression of resistance at $50^{\circ} \mathrm{F}$ indicated that there were no marked differences in the aphid populations on plants exposed to $50^{\circ} \mathrm{F}$ for different amounts of time. Populations on all of the C-902 plants were almost as high as on Caliverde, indicating that under these conditions they were highly susceptible. C-902 plants in the greenhouse exhibited a marked degree of resistance at this time, indicating that the plants were resistant at the time they were transferred to the $50^{\circ} \mathrm{F}$ room. This suggested that either the loss of resistance in the plants took place more rapidly than could be accurately measured by this technique, or that the change in expression of resistance was due mainly to a change in response in the aphids, rather than to a change in the plant. Data shown later will clarify this point. 


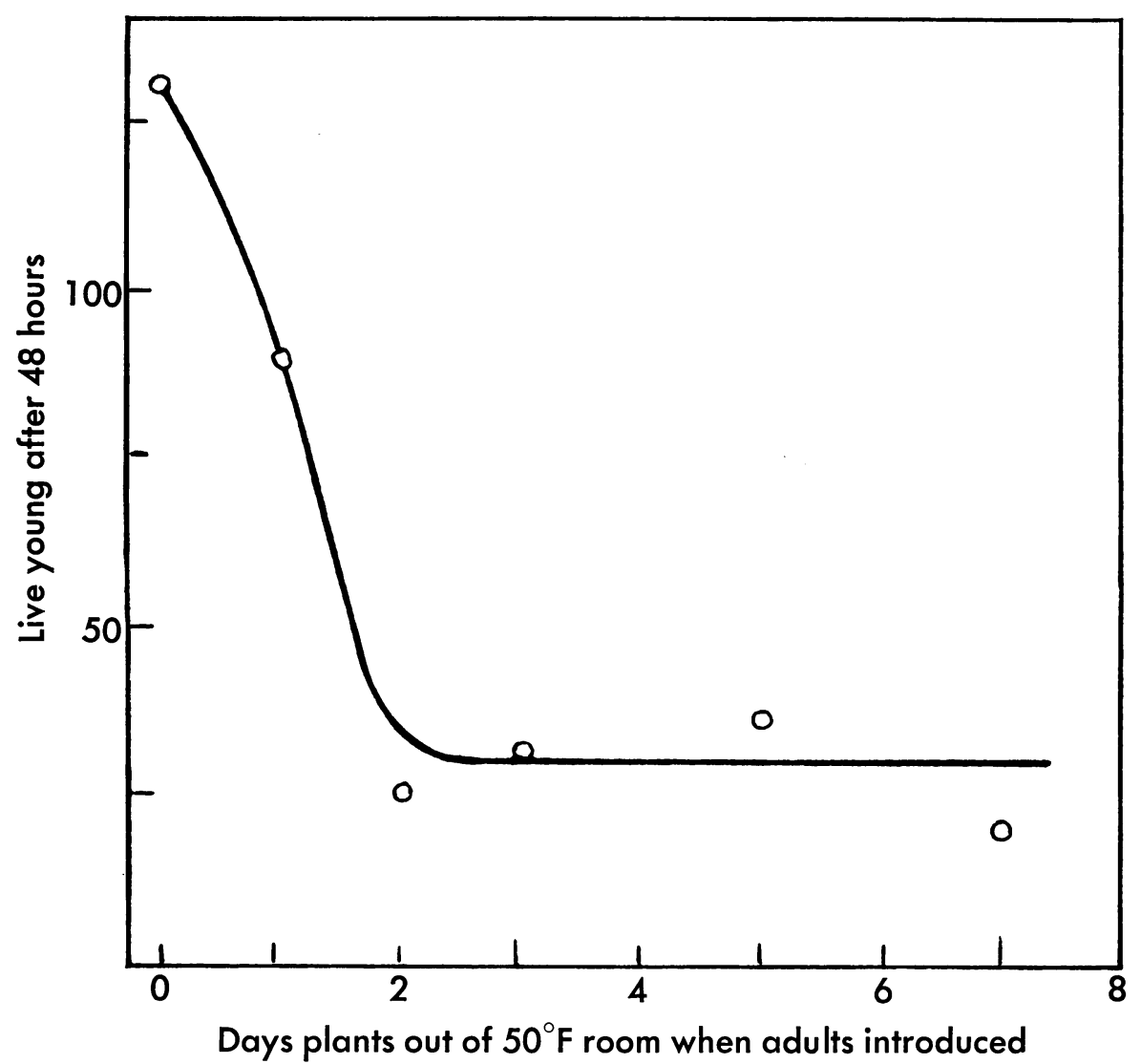

Fig. 7. Resistance of C-84 in relation to time exposed to high temperatures.

Table 4 shows counts of aphid populations on C-902 plants returned from cold to warm temperatures for various periods of time. It is seen that a definite trend was evident at the first count, 24 hours after the adult aphids were placed on the plants. The C-902 plants out of the $50^{\circ} \mathrm{F}$ room for 1 day or less at the time the adults were introduced appeared to be highly susceptible. The numbers of both live adults and young on these plants were comparable to those on Caliverde at the 24-hour count, indicating that these plants had retained most of the susceptibility which they possessed at $50^{\circ} \mathrm{F}$. By the $72-$ hour count, however, these plants had considerably lower numbers of aphids than the Caliverde plant, suggesting that resistance was being regained by this time. A chi-square analysis of live young after 24 hours indicated that the populations on the various C-902 plants differed significantly $\left(\chi^{2}=28.83\right.$, $\mathrm{P}=<.01)$; the same was indicated for the adult populations, though not until the 72-hour count $\left(\chi^{2}=14.87, \mathrm{P}=<.05\right)$. The contention is thus supported that $\mathrm{C}-902$ plants differed in resistance in relation to their time of exposure to $50^{\circ} \mathrm{F}$.

Figure 8 indicates that resistance in C-902 had reached its maximum level, under the existing conditions, in plants that had been out of the $50^{\circ} \mathrm{F}$ room 


\section{TABLE 4}

PERIODIC APHID COUNTS ON C-902 AND CALIVERDE PLANTS EXPOSED TO WARM TEMPERATURES FOR DIFFERENT TIME INTERVALS*

\begin{tabular}{|c|c|c|c|c|c|c|}
\hline \multirow{2}{*}{ Days plant out of $50^{\circ} \mathrm{F} \dagger$} & \multicolumn{2}{|c|}{24 Hours } & \multicolumn{2}{|c|}{48 Hours } & \multicolumn{2}{|c|}{72 Hours } \\
\hline & Live adults & Live young & Live adults & Live young & Live adults & Live young \\
\hline \multicolumn{7}{|c|}{ C-902 } \\
\hline $1 \ldots \ldots \ldots \ldots \ldots \ldots \ldots$ & 30 & 76 & 26 & 128 & 20 & 147 \\
\hline $2 \ldots \ldots \ldots \ldots \ldots \ldots$ & 28 & 54 & 23 & 88 & 12 & 100 \\
\hline $4 \ldots \ldots \ldots$ & 22 & 36 & 15 & 40 & 5 & 38 \\
\hline $6 \ldots \ldots \ldots \ldots$ & 24 & 36 & 18 & 39 & 5 & 26 \\
\hline Never at $50^{\circ} \mathrm{F} \ldots \ldots \ldots$ & 25 & 34 & 13 & 38 & 5 & 40 \\
\hline
\end{tabular}

Caliverde

\begin{tabular}{l|l|l|l|l|l|l|l}
\hline $6 \ldots \ldots \ldots \ldots \ldots \ldots$ & 30 & 60 & 30 & 155 & 29 \\
\hline
\end{tabular}

* Began tests with 30 adults per plant.

$\dagger$ Days out of the $50^{\circ} \mathrm{F}$ room at the time adults introduced.

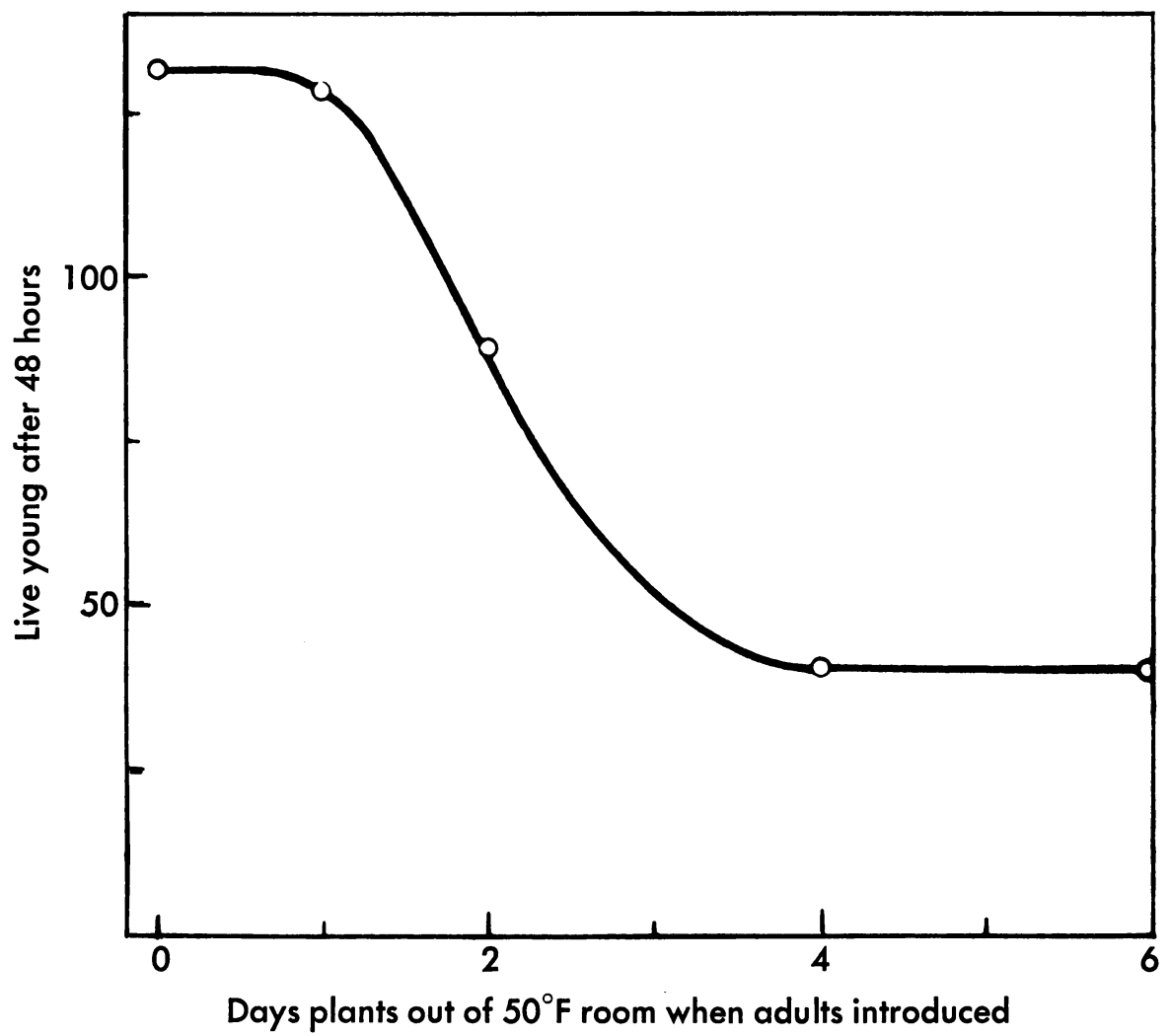

Fig. 8. Resistance of C-902 in relation to time exposed to high temperatures. 
for four days or more. This observation was supported by counts of both adults and young. A comparison with the populations on a C-902 plant which had not been at the $50^{\circ} \mathrm{F}$ temperature further indicates that resistance was completely regained in plants out of the $50^{\circ} \mathrm{F}$ room 4 and 6 days (table 4 ).

Tests with C-902 Using First-Instar Nymphs on Fxcised Stems. A more refined technique was employed in order to investigate whether there was any

TABLE 5

PERIODIC COUNTS OF LIVE YOUNG ON EXCISED SHOOTS REMOVED FROM $95^{\circ} \mathrm{F}$ AND EXPOSED TO 50 $\mathrm{F}$ FOR DIFFERENT

TIME INTERVALS

(Original number-40 aphids per shoot)

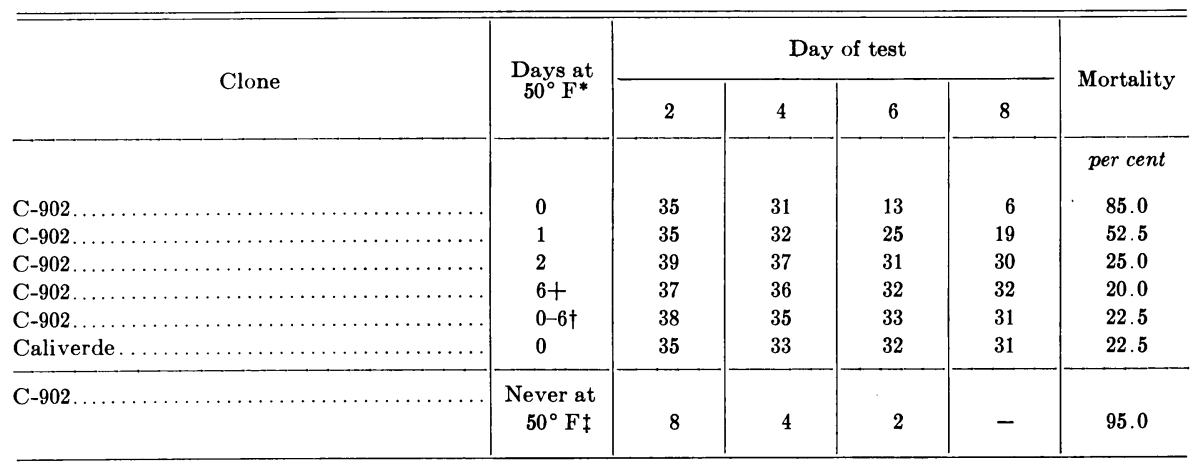

* Days excised shoots at $50^{\circ} \mathrm{F}$ when aphids introduced. Aphids transferred to fresh shoots, which had same respective temperature exposures as original shoots at start of test, after 2,4 , and 6 days.

$t$ Excised shoots taken from a plant moved from $95^{\circ} \mathrm{F}$ to $50^{\circ} \mathrm{F}$ at beginning of test. Fresh shoots removed from this plant after 2,4 , and 6 days had thus been exposed to $50^{\circ} \mathrm{F}$ for progressively longer periods.

$\ddagger$ Tested at $95^{\circ} \mathrm{F}$.

measurable length of time required for C-902 plants to lose their expression of resistance when moved from high to low temperatures. Table 5 indicates that differences not detectable by the previous techniques were evident. Chisquare analysis of the 8-day aphid counts indicated that population levels on the various treatments differed significantly $\left(\chi^{2}=41.4, \mathrm{P}=<.01\right)$. A markedly higher mortality occurred in aphids on the cuttings that were out of the $95^{\circ} \mathrm{F}$ room for less than 2 days when the aphids were introduced, indicating that these plants still maintained some of the resistance which they possessed at $95^{\circ} \mathrm{F}$. Table 5 , bottom line, shows that C-902 cuttings exhibited a high degree of resistance at $95^{\circ} \mathrm{F}$. On the other hand, cuttings from these same plants that were exposed to the low temperature for 2 days or more appeared to be nearly comparable to Caliverde in susceptibility. The mortality observed in these cases probably was due to the frequent transferring of nymphs, which, when disturbed, may have fallen or wandered off the cuttings. In Table 5 the designation of $0-6$ days out of the $95^{\circ} \mathrm{F}$ room refers to the cuttings of a plant on which aphids were introduced as soon as the plant was moved from $95^{\circ}$ to $50^{\circ} \mathrm{F}$. As in other treatments, aphids were transferred to fresh cuttings every 48 hours. The plant used as the source of these cuttings, however, was kept in the $50^{\circ} \mathrm{F}$ room for the remainder of the testing period. Thus, by the sixth day, when the nymphs had been transferred to fresh cuttings for the final time, the cuttings to which they were transferred 
had then been exposed to the $50^{\circ} \mathrm{F}$ temperature for 6 days. This essentially was comparable to the situation encountered when using the original technique where aphids were introduced and allowed to remain on plants that had just been brought from warm temperatures. The low mortality shown in table 5 indicates that this plant did not remain resistant long enough to cause a high degree of mortality of the aphids. This might explain why little or no

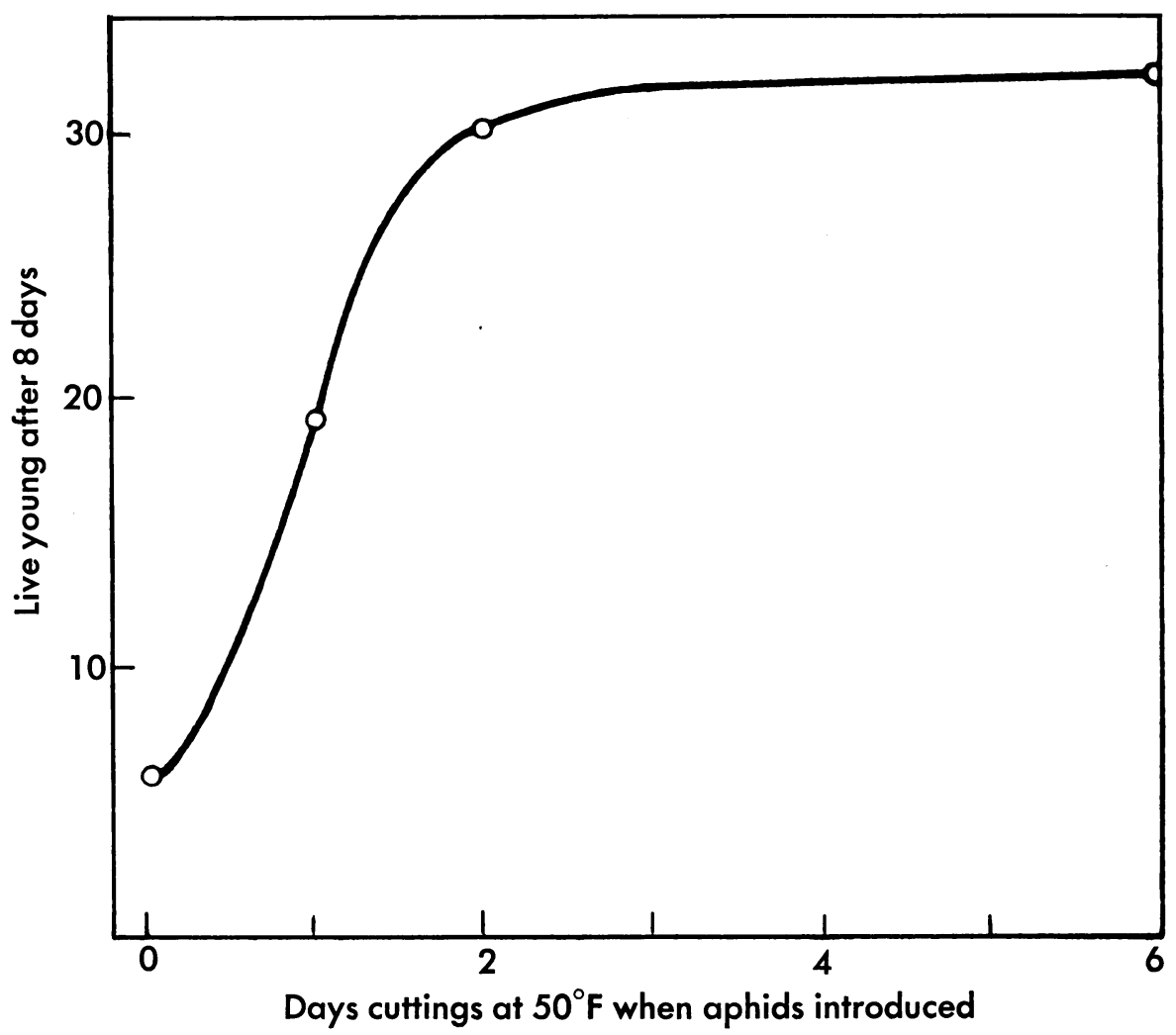

Fig. 9. Resistance of C-902 in relation to time exposed to low temperatures.

resistance in C-902 plants brought from warm temperatures could be detected by the other method.

Figure 9 indicates that the high temperature resistance in C-902 was lost after about two day's exposure to the $50^{\circ} \mathrm{F}$ temperature.

Discussion. The results of this series of experiments indicate that the change in expression of resistance, occurring when C-84 and C-902 plants are moved from high to low or low to high temperature, is due to a change in the host plant, which in turn affects the aphids. Observed differences in aphid populations on plants exposed to a new temperature for different lengths of time would necessarily be due to differences between plants, since aphids for each test series were placed on the plants at the same time. Inasmuch as aphids of each series were subject to similar external conditions, the only possible major variable was the condition of their food plants. 
It was clearly shown, however, that the aphids' reaction to resistance, in the form of mortality or low reproduction, is considerably slower at low than at high temperatures; this is especially evident in table 5. This fact appears to be due to the ability of the aphids to survive longer without food at low temperatures due to lower metabolic rate. To further investigate this point, 50 first-instar nymphs were confined in empty vials at $50^{\circ} \mathrm{F}$ and their mortality rate observed. Counts of remaining live aphids were as follows: 24 hours, $48 ; 48$ hours, $39 ; 72$ hours, $13 ; 120$ hours, $3 ; 144$ hours, 0 . Thus, if death of the aphids on the resistant plants is due to starvation, this would indicate that several days would be necessary for the effect of resistance in the form of mortality to appear. It then follows that if a plant showing resistance at high temperatures is moved to a low temperature, and aphids are immediately put on the plant, the aphids might be able to survive the effects of resistance and recover as the plant becomes more susceptible. This probably happened in clone C-902, where resistance apparently was lost in about two days. Therefore, it can be said that the lower expression of resistance (in terms of mortality) at low temperatures is due to a differential response of the aphid to resistance, as well as a change in the plant. The latter can be considered the most important factor, however.

It can be concluded that the change in resistance resulting from moving the plants to a higher or a lower temperature took place quite rapidly. The data indicate that with changing temperature, C-84 regained its resistance faster than it partially lost resistance, and that C-902 lost resistance faster than it regained it. This at first might suggest the possibility that resistance in the two elones involves different processes. However, it probably could also be explained on the basis that resistance is of the same nature in both clones. Though little is known of the actual nature of the resistance, it might be speculated that the unknown factor necessary for resistance is present at a high level in C-84, especially at high temperatures. When a C-84 plant is moved to low temperatures, the low temperature effect might produce a lower equilibrium level of the "resistance factor" after approximately five days, resulting in a somewhat lower degree of aphid resistance. When the plant is returned to a high temperature, the resistance factor, still at a fairly high level, may be rapidly built up to a level where complete or near-complete resistance returns.

In C-902, however, the resistance factor inherently may be at a fairly low level even at high temperatures. Thus, when these plants are moved to low temperatures, the factor responsible for resistance may be rapidly reduced below the threshold necessary to produce aphid resistance, and then may reach an equilibrium somewhere below this point. When the plants are again exposed to warm temperatures, a relatively long period of time could be necessary for the resistance factor to build up from a low level to an amount necessary to confer resistance to the aphid.

It has been demonstrated that change in resistance of C-84 and C-902 due to a change in temperature can take place in a matter of only a few days. It is further contended that leaves already fully expanded and mature are capable of undergoing this change, since aphids were confined on leaves that were fully expanded at the time the plants were moved to a different temperature. 
To further illustrate this, C-902 and Caliverde plants having aphids confined on single mature trifoliate leaves were transferred from the $50^{\circ} \mathrm{F}$ room to the greenhouse. At $50^{\circ} \mathrm{F}$ aphid colonies previously held on the plants for 6 days had increased to approximately the same numbers on both C-902 and Caliverde, indicating lack of resistance in the C-902 leaves. However, after these plants with their aphid colonies were returned to the greenhouse for several days, populations were considerably lower on C-902 than on Caliverde, thus demonstrating that the same leaves on C-902 which were susceptible at $50^{\circ} \mathrm{F}$ had become resistant when returned to warm temperatures.

The relatively rapid change in resistance of C-902 and C-84 with change in temperature, along with the ability of fully expanded mature leaves to undergo this change, tends to indicate that the resistance of these clones to the spotted alfalfa aphid is of a physiological rather than a morphological nature. This opinion was previously expressed by MeMurtry and Stanford (1960).

\section{Resistance at Alternating High and Low Temperatures}

It was shown in the first part of this section that C-84 and C-902 plants were more resistant at high than at low constant temperatures. The results demonstrated the importance of temperature as a controlling factor in resistance of these plants to the spotted alfalfa aphid. Under natural conditions, however, alfalfa plants are ordinarily exposed to daily fluctuating high and low temperatures. Under such conditions it appeared possible that either the high, the low, or the mean temperature might be the most important in determining the degree of resistance expressed at a particular time of the year. Field observations have thus far provided little information regarding this point. Therefore, an experiment to test resistance of C-84 and C-902 under controlled alternating temperatures was performed.

Procedure. Plant growth chambers used in previous constant temperature studies were again utilized. A $60^{\circ} \mathrm{F}$ night temperature and an $80^{\circ} \mathrm{F}$ day temperature were selected. Controls were adjusted manually at 12-hour intervals, being set at the high temperature from 9 A.M. to 9 P.M., and at the low temperature for the remaining 12 hours. The change in temperature was complete within one hour after adjusting the controls. The night temperature remained within a range of $56^{\circ}$ to $60^{\circ} \mathrm{F}$, while the day temperature varied within a range of $80^{\circ}$ to $84^{\circ} \mathrm{F}$, the mean temperature being approximately $70^{\circ} \mathrm{F}$. In a second growth chamber, a constant temperature of $70^{\circ} \pm 2^{\circ} \mathrm{F}$ (the mean of the alternating temperatures) was maintained for a comparison with the alternating temperature treatment. As in other controlled temperature experiments, the day length was adjusted to 16 hours.

Four plants each (replications) of Caliverde, C-84, and C-902 were introduced from the greenhouse into each chamber. Aphids were placed on the plants 14 days later. Five adult female aphids were introduced into each of two leaf cages per plant, resulting in 10 adults confined to each plant and 40 per clone for each treatment. Live aphids were counted daily for a period of five days.

Results and Discussion. Table 6 shows the mean values of live aphids (mean of four replications) after five days. It is seen that C-84 exhibited near or complete immunity at both the constant and alternating tempera- 
tures. The C-902 clone exhibited a rather intermediate degree of resistance at both treatments, though aphid survival was somewhat higher at the $70^{\circ} \mathrm{F}$ constant temperature. An analysis of variance revealed no significant differences in total live aphids between the constant and alternating temperatures.

Previous data indicated that at $60^{\circ} \mathrm{F}$, C-902 was highly susceptible and C-84 partially susceptible, whereas at $76^{\circ}$ to $85^{\circ} \mathrm{F}, \mathrm{C}-902$ appeared quite highly resistant, and C-84 appeared immune. Therefore, at alternating temperatures of $60^{\circ}$ and $80^{\circ} \mathrm{F}$, should the low temperature be the most important

TABLE 6

EFFECT OF CONSTANT AND ALTERNATING TEMPERATURES ON APHID SURVIVAL AND REPRODUCTION ON RESISTANT AND SUSCEPTIBLE ALFALFA CLONES*

\begin{tabular}{|c|c|c|c|c|c|c|}
\hline \multirow{3}{*}{ Temperature ${ }^{\circ} \mathrm{F}$} & \multicolumn{6}{|c|}{ Alfalfa clone } \\
\hline & \multicolumn{2}{|c|}{$\mathrm{C}-84$} & \multicolumn{2}{|c|}{ C-902 } & \multicolumn{2}{|c|}{ Caliverde } \\
\hline & Adults & Young & Adults & Young & Adults & Young \\
\hline $60-80 \ldots$. & 0.0 & 0.0 & 3.3 & 78.0 & 10.0 & 226.0 \\
\hline $70 \ldots \ldots \ldots \ldots \ldots \ldots \ldots \ldots$ & 0.5 & 1.8 & 5.0 & 97.0 & 9.8 & 235.0 \\
\hline
\end{tabular}

* Based on live aphids per replication five days after adults were placed on the plants.

in determining the amount of resistance expressed, it might be expected that the plants would show a degree of resistance similar to the constant temperature of $60^{\circ} \mathrm{F}$. Conversely, if the high temperature were the controlling factor. the degree of resistance should be similar to that at a constant temperature in the range of $80^{\circ} \mathrm{F}$. Insofar as the C-84 and C-902 plants both were expressing a considerably higher degree of resistance at the alternating temperatures than was previously found at a constant temperature of $60^{\circ} \mathrm{F}$, it was apparent that the low temperature did not determine the degree of resistance. Also, C-902 was found to be more susceptible at the $60^{\circ}$ to $80^{\circ} \mathrm{F}$ alternating temperatures than was observed at the high constant temperatures $\left(76^{\circ}\right.$ and $\left.85^{\circ} \mathrm{F}\right)$, suggesting that the high temperature likewise was not the controlling factor. This point is illustrated in figure 10, which shows the relative resistance of C-902 under the various temperature conditions expressed as per cent reduction in live aphids after five days compared with the Caliverde check. ${ }^{\circ}$ The values shown for the $60^{\circ}$ and $80^{\circ} \mathrm{F}$ constant temperatures were taken directly from the graph of resistance in relation to temperature in figure 4 . Figure 10 indicates that the degree of resistance expressed at the $60^{\circ}$ to $80^{\circ} \mathrm{F}$ alternating temperatures resembled most closely that found at the $70^{\circ} \mathrm{F}$ mean temperature. Thus, it would appear that the degree of resistance expressed was more closely correlated with the mean rather than the high or the low temperatures. The fact that differences in aphid numbers between the alternating and the mean temperatures were not significant is in agreement with this interpretation. This could not be as clearly shown for C-84, since these plants were nearly immune at both the mean and the high temperatures.

\footnotetext{
${ }^{6}$ Per cent reduction $=\frac{\text { Aphids per plant on Caliverde }- \text { A phids per plant on C-902 }}{\text { Aphids per plant on Caliverde }} \times 100$.
} 


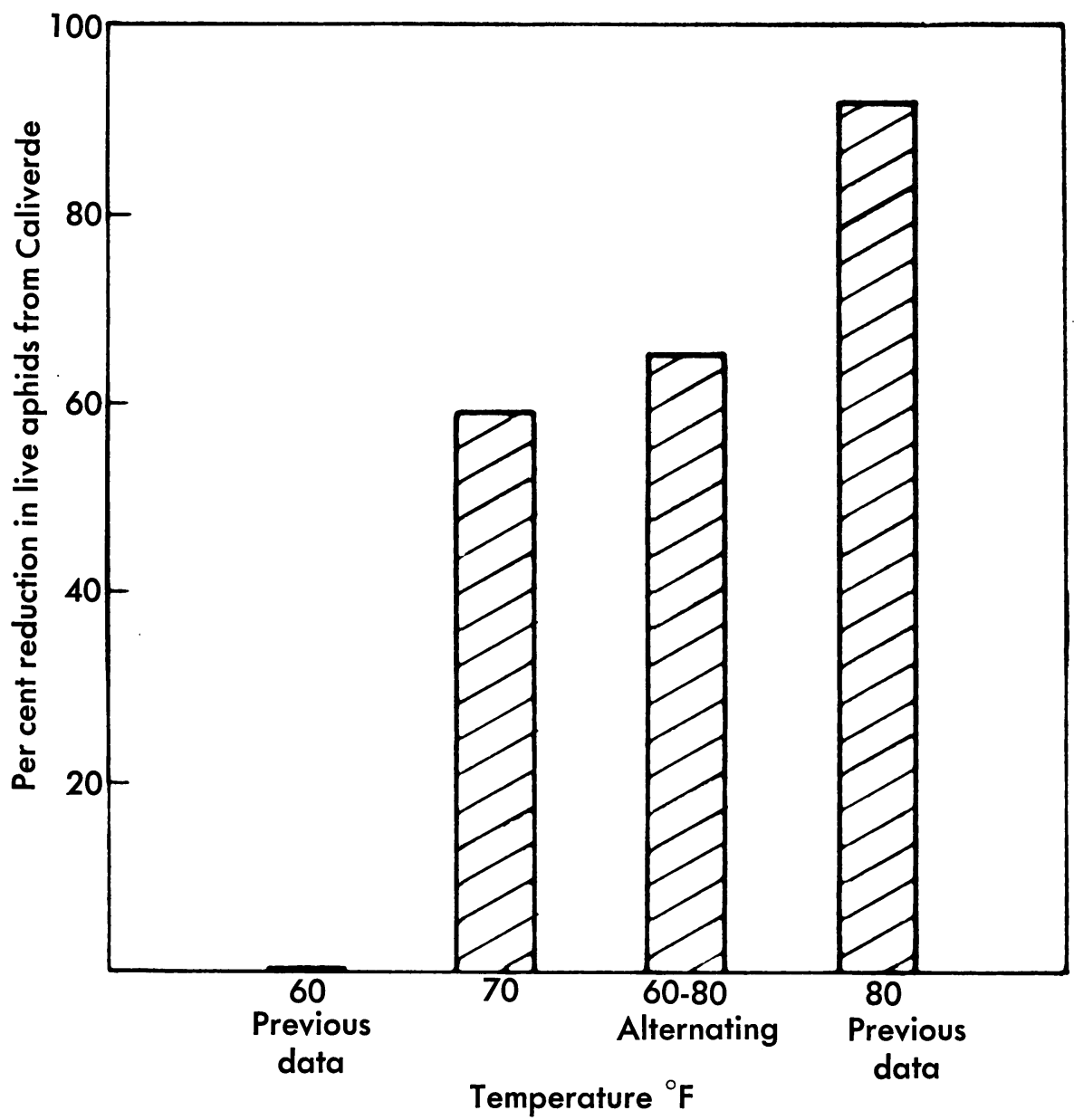

Fig. 10. Resistance of clone C-902 at $60-80^{\circ} \mathrm{F}$ alternating temperatures in comparison with two constant temperatures. $\left(60^{\circ}\right.$ and $80^{\circ} \mathrm{F}$ values taken from fig. 5 .)

It was previously indicated that C-902 plants, when moved to a low temperature, lost resistance at a faster rate than they regained resistance when returned to high temperatures. This might lead one to expect that under the alternating high and low temperatures of this experiment the C-902 plants would have become progressively less resistant. But such did not appear to be the case. It does not seem likely, however, that such an effect would occur when the temperatures were changed at intervals of as short as 12 hours. Should the temperature have been changed at intervals of several days, the effect may not have been the same.

\section{RESISTANCE IN RELATION TO PHOTOPERIOD}

Photoperiod is known to affect various processes in insects and plants. Lees (1955) indicated that photoperiod controls the induction of diapause in certain insects. He also demonstrated that photoperiod is a regulating factor 
in form determination of the aphid Megoura viciae Buckton (Lees, 1959). In plants, photoperiod affects such processes as flowering, vegetative growth, tuberization, and bulb formation (Meyer and Anderson, 1952). These processes are associated with a complex of internal changes in the plant, and it is conceivable that such changes could affect the susceptibility of the plant to an insect. Since it was known that some plants resistant to the spotted alfalfa aphid became more susceptible at certain times of the year, it appeared possible that photoperiod, as well as temperature, might be involved. This possibility was investigated in the experiment reported below.

Procedure. A test for possible effects of photoperiod on the expression of resistance was carried out with the aid of light-tight chambers in the greenhouse. The light source in the chamber consisted of fluorescent tubes and incandescent bulbs which provided a total intensity of about 500 footcandles to the upper portions of the alfalfa plants. Electric fans furnished continuous ventilation. Temperatures ranged from about $69^{\circ}$ to $73^{\circ} \mathrm{F}$. Two photoperiod treatments were employed, one being 8 hours and the other 18 hours. Three plants of each of the clones (C-84, C-902, and Caliverde) were used in each of the photoperiod treatments. The plants, on movable carts, were brought out of the chambers for 8 hours daily in order to utilize normal daylight. Thus, the plants receiving a total of 18 hours photoperiod were then exposed to an additional 10 hours of light inside the chamber. Ten adult aphids were placed on a caged terminal of each plant after the plants had been exposed to the desired light treatments for a period of 16 days. After aphids were introduced, the plants were kept in the chambers except when counts were being made. Plants thus received only artificial light for the remainder of the test. A similar test was performed in the $50^{\circ} \mathrm{F}$ room of the insectary. Procedures were the same, except that the plants were exposed only to artificial light for the entire experiment.

Results and Discussion. Tests for effects of photoperiod on resistance yielded negative results. There were no significant differences between treatments in numbers of aphids present at the end of the tests. Plant growth was affected, as the plants exposed to the long photoperiod grew taller and had darker green foliage. The results suggest that variability in the expression of resistance is probably not correlated with day length. Therefore, it would appear that low temperature acts independently of day length in reducing the expression of resistance to the aphid during the cooler seasons of the year.

\section{RESISTANCE IN RELATION TO SOIL MOISTURE}

The literature pertaining to aphid populations as affected by the water status of their host plants has been reviewed by Kennedy et al. (1958). Apparently, plants growing under drought conditions can be either favorable or detrimental to aphid colonization, depending upon the species of aphid, species of host plant, degree of moisture stress, and various other conditions involved. Maxwell and Painter (1959) observed a lower rate of honeydew production by the greenbug, Toxoptera graminum (Rond.), on wilted leaves, but found no significant differences in excretion by spotted alfalfa aphids on wilted or turgid plants.

Kennedy et al. (1958) demonstrated that populations of Aphis fabae Scop. 
on potted plants left unwatered had a lower reproductive rate than aphids on watered plants. They believed that this was due to lower turgor pressure or increased viscosity of sap in the phloem of wilted leaves, which may have resulted in a reduced uptake of sap by the aphids. Kennedy and Mittler (1953) and Mittler (1957) had previously presented evidence that turgor pressure in the phloem of the host plant played a major role in the rapid uptake of phloem sap by Aphis fabae and Tuberolachnus salignus (Gmelin).

Since water stress of the host plant has been shown to affect aphid infestations, it seemed possible that this might also affect the expression of host resistance to the spotted alfalfa aphid. The object of the following experiments, therefore, was to determine whether water deficiency could alter the resistance of C-84 or C-902 plants.

Procedure. Two tests were carried out, one in the greenhouse and one in the $50^{\circ} \mathrm{F}$ room. The greenhouse test was initiated in January when greenhouse temperatures were ranging from $72^{\circ}$ to $80^{\circ} \mathrm{F}$. Caliverde, C-902, and C-84 plants were used. The plants were cut back and transferred to 12-inch pots so that the soil moisture would be depleted more slowly than in smaller pots. After the plants had become established, normal watering was discontinued in one group of plants. These plants were then given only sufficient water to prevent the foliage from drying up, so that the plants were severely wilted most of the time. Aphids were confined on the plants five days after wilting was observed in the inadequately watered plants. Total live aphids were counted for a period of five days.

In the test carried out at $50^{\circ} \mathrm{F}$, only C-902 and Caliverde plants were used. The plants were left in small pots, since soil moisture was not rapidly depleted at this temperature. As in the greenhouse test, normal watering was discontinued on one group of plants. When small amounts of water were added to prevent leaves from dying, the leaves usually recovered at least part of their turgidity for about one day. Adult aphids were placed on the plants five days after initial wilting commenced and were allowed to reproduce for a period of seven days.

Results and Discussion. There were no significant differences in reproduction of aphids between watered or unwatered plants in either of the tests. The drought conditions could not be shown to affect the aphid populations on either the resistant or susceptible clones. If the uptake of phloem sap by this aphid is dependent mainly on turgor pressure in the phloem, it might be expected that wilted leaves would have insufficient turgor pressure to force the sap through the stylet food channel at the normal feeding rate, which would result in lower reproduction and survival as suggested by Kennedy et al. (1958). However, it is possible that under the conditions of these experiments the phloem itself had not lost sufficient turgor pressure to cause a serious reduction in the rate of uptake of phloem sap by the aphids.

It was noted that caged leaves of the water-deficient plants became more severely chlorotic from aphid feeding than did the infested leaves on watered plants. This suggests that plants growing under water stress might be more susceptible to the aphids than plants receiving adequate water, since a given amount of feeding apparently would result in greater injury to the former plants. 


\section{RESISTANCE IN RELATION TO PLANT NUTRIENT DEFICIENCIES}

Various workers have found that insect populations can be affected by varying the concentration of essential nutrient elements available to their host plants. In some cases, plants normally susceptible to a particular species of insect apparently have become resistant when grown in a medium having a deficiency or an excess of a certain element. The literature regarding this form of induced resistance has been reviewed by Painter $(1951,1954)$. The concentration of nutrient elements might also be important in affecting the expression of resistance in plants normally resistant to a species of insect. This has been discussed by Painter (1954) in the following statement: "So far as plant resistance is concerned, there may be two different classes of edaphic effects. In the first place, differences arising from soil treatments may be a source of variation in resistance from time to time and from place to place, thus affecting the expression of resistance. In contrast, these soilplant-insect relationships may also involve a mechanism of resistance since certain species and varieties of plants when grown in the same kind of soil may differ through differing abilities of the varieties to utilize the chemical elements present in the soil."

Possible nutrient level affects on resistance appeared to warrant a detailed investigation in the case of host resistance to the spotted alfalfa aphid. Since the expression of resistance of many of the plants has been observed to vary from time to time and from place to place, it seemed possible that responses of the resistant plant to different nutrient levels in the soil might well be a factor involved. Thus, by means of nutrient culture techniques, experiments were conducted to determine whether the expression of resistance in C-84 and C-902 would be affected by growing the plants in media deficient in any one of several major essential elements.

Procedure. Cuttings of C-84, C-902, and Caliverde were rooted in vermiculite in $1 / 2$-gallon glazed porcelain crocks having a side drainage hole at the bottom. Several cuttings of one clone were placed in each crock and watered twice daily with distilled water for the first five days. At that time, watering with the desired nutrient solutions was begun and was continued every other day. On the alternate days, cuttings were watered with distilled water only. Crocks containing the plants were divided into four main groups, each receiving a different nutrient solution treatment. The treatments consisted of a nitrogen-deficient, a phosphorus-deficient, a potassiumdeficient, and nondeficient or complete solution. Each treatment was made up of nine crocks of cuttings, which consisted of three crocks of each of the three clones.

The various nutrient solutions were patterned essentially after Hoagland and Arnon (1950), being prepared from stock solutions as follows:

1. Solution lacking nitrogen

$0.5 \mathrm{M} \mathrm{K}_{2} \mathrm{SO}_{4}$

$1 \mathrm{M} \mathrm{M}_{\mathrm{g}} \mathrm{SO}_{4} \cdot 7 \mathrm{H}_{2} \mathrm{O}$

$0.05 \mathrm{M} \mathrm{Ca}\left(\mathrm{H}_{2} \mathrm{PO}_{4}\right)_{2} \cdot \mathrm{H}_{2} \mathrm{O}$

$0.01 \mathrm{M} \mathrm{Ca} \mathrm{SO}_{4}$ cc in 1 liter of

nutrient solution 
2. Solution lacking phosphorus

$\left.1 \mathrm{M} \mathrm{Ca}\left(\mathrm{NO}_{3}\right)_{2} \cdot 4 \mathrm{H}_{2} \mathrm{O}\right)$

$1 \mathrm{M} \mathrm{KNO}_{3}$

$1 \mathrm{M} \mathrm{Mg} \mathrm{SO}_{4} \cdot 7 \mathrm{H}_{2} \mathrm{O}$

3. Solution lacking potassium

$1 \mathrm{M} \mathrm{Ca}\left(\mathrm{NO}_{3}\right)_{2} \cdot 4 \mathrm{H}_{2} \mathrm{O}$

$1 \mathrm{M} \mathrm{MgSO}_{4} \cdot 7 \mathrm{H}_{2} \mathrm{O}$

$0.05 \mathrm{M} \mathrm{Ca}\left(\mathrm{H}_{2} \mathrm{PO}_{4}\right)_{2} \cdot \mathrm{H}_{2} \mathrm{O} \quad 10$

4. Nondeficient solution

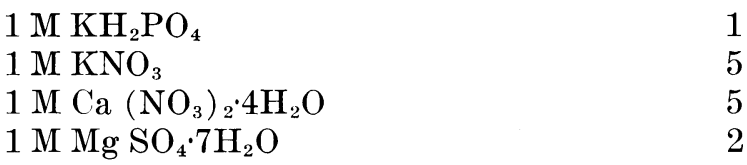

Iron was supplied to all nutrient solutions from a stock solution containing $25 \mathrm{gr}$ of sodium ferric diethylenetriamine penta-acetate (iron chelate) per liter of water. This was added to the nutrient solutions at the rate of 1 ce per liter. In addition, a supplementary solution containing the essential microelements was prepared as follows:

Compound

$\mathrm{H}_{3} \mathrm{BO}_{3}$

$\mathrm{MnCl}_{2} \cdot 4 \mathrm{H}_{2} \mathrm{O}$

$\mathrm{ZnSO}_{4} \cdot 7 \mathrm{H}_{2} \mathrm{O}$

$\mathrm{CuSO}_{4} \cdot 5 \mathrm{H}_{2} \mathrm{O}$

$\mathrm{H}_{2} \mathrm{MoO}_{4} \cdot \mathrm{H}_{2} \mathrm{O}$
Grams dissolved in

1 liter of $\mathrm{H}_{2} \mathrm{O}$

2.86

1.81

0.22

0.08

0.02

One cc of this solution was added to each liter of nutrient solution.

Distilled water was used in all preparations. Prepared solutions were kept in 5-gallon glass containers, which were painted on the outside with an aluminum paint to prevent entrance of light and growth of algae.

Cuttings watered with the nitrogen- and phosphorus-deficient solutions made almost no additional growth after the first 2 or 3 weeks in the crocks; therefore, it was found desirable to supplement the solutions with low concentrations of the deficient element. Molar $\mathrm{KNO}_{3}$ and $\mathrm{Ca}\left(\mathrm{NO}_{3}\right)_{2} \cdot 4 \mathrm{H}_{2} \mathrm{O}$ each were added to the nitrogen-deficient solution at a rate of $0.5 \mathrm{ml} / 1(1 / 10$ of the amount present in the complete nutrient solution). Molar $\mathrm{KH}_{2} \mathrm{PO}_{4}$ was added to the phosphorus-deficient solution at a rate of $0.05 \mathrm{ml} / 1(1 / 20$ of the amount present in the complete solution). The plants received these supplements at weekly intervals for a period of approximately 5 weeks.

Plants watered with the potassium-deficient solution did not develop deficiency symptoms under the procedure previously described. There appeared to be at least two possible explanations for this. First, the vermiculite may have contained potassium which the plants were able to utilize; second, the porcelain crocks may have contained some material which was releasing potassium ions into the medium. Therefore, the procedure was altered and a new group of cuttings were rooted in a medium of perlite material in place of vermiculite. In addition, a coating of aluminum paint was applied to the inside of the crocks. Under these conditions potassium deficency symptoms rapidly appeared in the plants. 
The study consisted of three separate experiments in which one of the nutrient-deficiency treatments was compared with the nondeficient check plants in each case. The phosphorus-deficient plants were tested for resistance in the middle of December, at which time the temperatures in the greenhouse ranged from $68^{\circ}$ to $75^{\circ} \mathrm{F}$. Plants watered with the nitrogen-deficient solution were tested during the first week of January at temperatures of $65^{\circ}$ to $75^{\circ} \mathrm{F}$. The testing of plants growing in the potassium-deficient medium was carried out in May when the greenhouse temperatures ranged from $72^{\circ}$ to $92^{\circ} \mathrm{F}$. The latter cuttings were tested for resistance about 6 weeks after being rooted, while the nitrogen- and phosphorus-deficient plants were tested approximately three months after they were rooted.

TABLE 7

LIVE APHIDS PER REPLICATION AFTER FIVE DAYS* ON PLANTS WATERED WITH PHOSPHORUS-DEFICIENT AND COMPLETE NUTRIENT SOLUTIONS

\begin{tabular}{|c|c|c|c|c|}
\hline \multirow{2}{*}{ Clone } & \multicolumn{2}{|c|}{ Phosphorus-deficient } & \multicolumn{2}{|c|}{ Complete } \\
\hline & Adults & Young & Adults & Young \\
\hline C-84. & 0.3 & 0.0 & 4.7 & 12.0 \\
\hline $\mathrm{C}-902 \ldots \ldots \ldots \ldots \ldots \ldots \ldots \ldots \ldots \ldots \ldots$ & 5.7 & 49.0 & 8.0 & 114.0 \\
\hline Caliverde.............................. & 9.7 & 144.0 & 9.3 & 146.0 \\
\hline
\end{tabular}

* Five days after adult aphids were placed on plants.

Test aphids were caged on the plants by means of the small leaf cages. In the case of the phosphorus-deficient plants, two to three trifoliate leaves were confined in each cage because of the small size of the leaves on these plants. On plants growing in all of the other nutrient solutions, a single trifoliate leaf was confined in each cage. One cage, in which five adult aphids were placed, was used on each of two different cuttings growing in a crock. Each crock being considered a replication, this resulted in 10 adult aphids per replication, 30 per clone, and 90 for each nutrient solution treatment. Counts of live adults and young were made periodically.

Nitrogen Deficiency. Prior to the time the plants were supplemented with low concentrations of $\mathrm{Ca}\left(\mathrm{NO}_{3}\right)_{2}$ and $\mathrm{KNO}_{3}$, the top growth was spindly and leaves extremely chlorotic. A marked response was obtained after these materials were added to the nutrient solution several times, though at the time of testing, the plants were still reduced in size and possessed chlorotic leaves in comparison with the nondeficient check plants. The counts of live aphids after five days showed no marked differences within a given clone between the nitrogen-deficient and nondeficient plants. Thus, it would appear that nitrogen level probably is not a factor in determining the level of resistance or susceptibility expressed. It is possible, of course, that if the plants had demonstrated very extreme deficiency symptoms when tested the effect may not have been the same.

Phosphorus Deficiency. Phosphorus-deficient plants were extremely stunted in comparison with the check plants. The internodes were short and the leaves very small. Most shoots did not reach a length of more than three to four inches. Table 7 shows counts of live aphids on the plants after five 
days. It is apparent that the populations on the two resistant clones were consistently lower on the plants watered with the phosphorus-deficient solution. The differences between the two treatments were highly significant. On the other hand, it can be seen that the susceptibility of the Caliverde plants was not affected. A highly significant interaction between clones and nutrient solution treatments supports the view that the aphids were not affected by the phosphorus deficiency in the same way on both the resistant and susceptible clones. Therefore, it can be inferred that in a phosphorus-deficient medium, C-84 and C-902 became more resistant, while Caliverde retained its normal degree of susceptibility.

AVERAGE VALUES (OF THREE REPLICATIONS) OF PER CENT ELEMENTAL PHOSPHORUS IN DEFICIENT AND NONDEFICIENT ALFALFA PLANTS

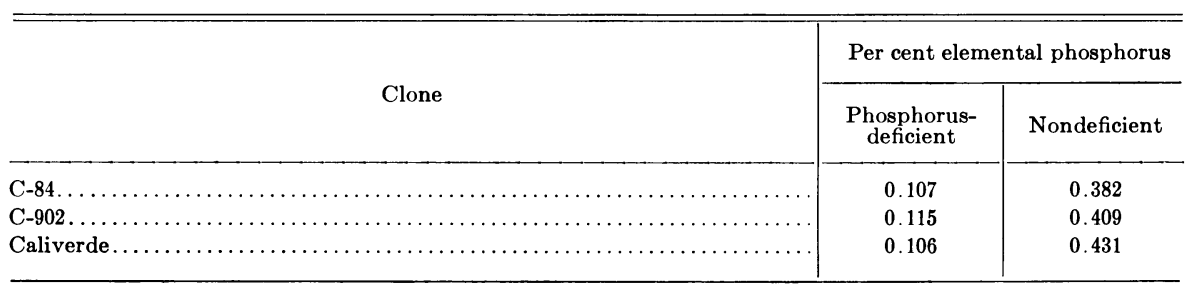

The deficient and nondeficient plants were analyzed for phosphorus content essentially according to the method of Johnson and Ulrich (1959). Table 8 shows the results of the analysis. All three clones had approximately the same degree of phosphorus deficiency, and therefore equally low phosphorus levels affected only the resistant clones in their suitability to the aphids.

There could be at least two possible explanations for this phenomenon: (1) Aphids surviving on the resistant plants may have been in a weakened condition and thus the added effect of phosphorus deficiency, as well as inherent resistance in the plant, could have resulted in a higher mortality and lower fecundity than on a nondeficient resistant plant. Aphids on Caliverde plants, being in vigorous condition, may not have been markedly affected by the condition of phosphorus deficiency. (2) The factor responsible for resistance in C-84 and C-902 may have been intensified by low levels of phosphorus in the plants. In other words, phosphorus deficiency may or may not have had a direct effect on the factor which produces resistance in the plants.

Some of the known effects of phosphorus deficiency in plants have been mentioned by Meyer and Anderson (1952). Apparently, the rate of protein synthesis is reduced. Correlated with a decrease in protein synthesis, there is often an accumulation of sugars in the vegetative organs of the plant.

Potassium Deficiency. Plants watered with the potassium-deficient solution showed a white spotting around the margins of the leaflets and pronounced chlorosis of many of the leaflets, developing first around the margins. The white spotting is described by Bear and Wallace (1950) as being an almost sure sign of potassium deficiency in alfalfa. Caged leaves on the 
potassium-deficient plants appeared to be less tolerant to high numbers of aphids than the check plants. On the eaged Caliverde leaves, there was extreme injury (necrosis beginning) by the fourth day, and the increase in numbers of young aphids was considerably less than on the previous days. This indicated that due to increased injury, leaves had become less favorable to the aphids. This was considered to be a condition produced by high numbers of aphids, rather than an original unfavorableness of the potassiumdeficient Caliverde plants. As this was an undesirable effect for the purpose of the experiment, aphid counts were not recorded beyond the third day.

Table 9 shows the average aphid counts after 3 days. It is seen from these

TABLE 9

LIVE APHIDS PER REPLICATION AFTER THREE DAYS* ON PLANTS WATERED WITH POTASSIUM-DEFICIENT AND COMPLETE NUTRIENT SOLUTIONS

\begin{tabular}{|c|c|c|c|c|}
\hline \multirow{2}{*}{ Clone } & \multicolumn{2}{|c|}{ Potassium-deficient } & \multicolumn{2}{|c|}{ Complete } \\
\hline & Adults & Young & Adults & Young \\
\hline C-84.. & 6.3 & 63.0 & 2.0 & 7.0 \\
\hline 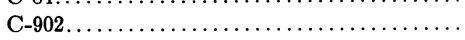 & 9.7 & 141.0 & 5.0 & 69.0 \\
\hline Caliverde $\ldots \ldots \ldots \ldots \ldots \ldots \ldots \ldots \ldots$ & 10.0 & 180.0 & 10.0 & 183.0 \\
\hline
\end{tabular}

* Three days after adult aphids were placed on plants.

data that on Caliverde there were nearly equal numbers of live aphids on both deficient and nondeficient plants. However, on the two resistant clones, there were consistently higher numbers of live aphids (within clones) on the plants watered with the potassium-deficient solution. An analysis of variance of total live aphids after 3 days showed highly significant differences in numbers of aphids between the two nutrient solution treatments. Further analysis showed that the source of the significance was the difference between treatments in the C- 84 plants. Though there were considerably more live aphids on the potassium-deficient plants in the case of C-902 as well, significance was not established due to a large variation between replications.

Potassium deficiency, therefore, apparently produced an effect opposite to that of phosphorus deficiency, e.g. the resistant clones showed a decrease rather than an increase in their degree of resistance. Though the differences could not be shown to be significant in the case of C-902, the plants receiving the deficiency treatment did appear more susceptible, as in C-84 where the effect was found to be highly significant. Thus, since the trend was in the same direction in both clones, it appears that the potassium level may in some way be connected with the process which endows resistance of the plants to the spotted alfalfa aphid.

It is not possible to say how potassium might be related to the aphidresistance process, since this element is involved in numerous roles in the physiology of plants, many of which are obscure (Meyer and Anderson, 1952). According to these authors, potassium has a regulatory or eatalytic role in plant metabolism. Plants deficient in this element usually contain a higher percentage of soluble organic nitrogen compounds (amino acids and amides) and a lower protein content than plants supplied with adequate 
potassium. Meyer and Anderson indicate that the carbohydrate metabolism is also disturbed, and that earbohydrates rapidly decrease in quantity probably as a result of decreased photosynthesis and increased respiration.

There is some circumstantial evidence which indicates that a low potassium content of the host plant or in the soil may be more favorable to some insects. Schoene (1941) observed that a high nitrogen content seemed to favor an increase in populations of the mealybug Pseudococcus comstocki (Kuw.) on apples. He stated that one of the effects of a high nitrogen ratio is a reduced amount of potassium in the fruit, and suggested that the increased multiplication of mealybugs might also be associated with low potassium content. Painter (1951) cites a similar case.

\section{RESISTANCE IN RELATION TO LEAF AGE OF THE HOST PLANT}

The age or stage of growth of a host plant often has been shown to have a considerable effect on the degree of infestation of a certain species of sucking insect. Kennedy et al. (1950) found that young growing or senescent leaves of certain plants were more susceptible to the aphids Myzus persicae (Sulz.) and Aphis fabae than mature green leaves. To account for this, they formulated the hypothesis that the aphid's food (phloem sieve tube sap) would be specifically rich in soluble organic nitrogen compounds (e.g., amino acids and amides) during rapid growth and again during senescence of the leaves, but poor in these compounds when neither growth nor senescence was in progress, as in mature leaves. In other words, it was suggested that the phloem sap should be rich in amino acids and amides during growth of the leaves as protein synthesis takes place, and again during senescence when proteins are hydrolyzed into amino acids and amides. Lindemann (1948) and Mittler (1958) came to similar conclusions in experiments with Cryptomyzus ribis (L.) and Tuberolachnus salignus, respectively, and presented quantitative evidence to support this contention.

Emery (1946) observed that new growth of an alfalfa plant was more favorable to pea aphids than older growth on the same plant. Dahms (1948) found that antibiosis of chinch bugs on resistant sorghums was more pronounced in seedlings than in older plants.

Thus, it is seen that the physiological age of the host plant or plant part can be important in determining the potential degree of infestation by an insect. It appeared possible that this could also be a factor which might alter the expression of host-plant resistance to the spotted alfalfa aphid.

Procedure. Greenhouse experiments were designed to compare aphid survival and reproduction on young leaves with that on mature leaves. A preliminary test, using only susceptible Caliverde plants, was carried out in May at greenhouse temperatures of $72^{\circ}$ to $86^{\circ} \mathrm{F}$. A second test, using the two resistant clones, was performed in January at temperatures of $72^{\circ}$ to $80^{\circ} \mathrm{F}$. To confirm results of this test, another was carried out the following May during which time the temperatures ranged from $72^{\circ}$ to $85^{\circ} \mathrm{F}$. In the latter test, only C-902 plants were used.

Plants of two different growth eategories were used in the experiments, 
one category consisting of plants recently cut back and possessing young growth with shoots only a few inches high, and the other category consisting of plants having mature shoots which had ceased elongating. For each clone tested there were three plants or replications of both growth categories. In the January test, the plants with mature growth were not flowering, but leaves utilized were definitely in a state of mature growth, as vegetative growth had ceased. In the other tests; mature shoots were flowering, with some petal drop already occurring. Individual leaves were confined in the small leaf cages. In plants with mature growth, leaves about halfway down the shoots of plants were selected, while on plants having young growth, the first unfolded leaf of a shoot was used. Adult aphids were placed in the cages, and live adults and young were counted daily for five days thereafter.

Results and Discussion. Results of these experiments were negative. Neither the susceptibility of Caliverde nor the resistance of C-84 and C-902 could be shown to vary with the age of the leaves on which the aphids were feeding. If the conclusion by various workers that the nitrogen content of the phloem sap is higher in young than in mature leaves can also be applied to alfalfa, it might be said that soluble nitrogenous compounds are of sufficient concentration for this aphid in both young and mature leaves.

\section{DISCUSSION}

It has been shown that variations in temperature and mineral nutrition can affect the apparent degree of resistance expressed by clones C-84 and C-902. It is probable that temperature would be the most important factor under natural conditions. Though potassium and phosphorus nutrition had a pronounced effect on host resistance in the experiments here reported, it is not known whether variations in these factors in the field would be of sufficient magnitude to produce such a marked response. Temperature, however, varies considerably with the season and even from day to day. Within a certain range, a small change in the temperature was shown to result in a considerable change in the expression of resistance (fig. 4). It was also found that the mean temperature, rather than the high or low, may be important in determining the level of resistance. If this is true under natural conditions, plants intermediate in resistance, such as C-902, might be greatly affected by small variations in the mean temperature. For example, the resistance of C-902 was found to be very sensitive to changes in temperature in the range of about $68^{\circ}$ to $76^{\circ} \mathrm{F}$, a range in which mean temperatures might often vary during the growing season.

The effects produced by phosphorus and potassium deficiency of the host plant are examples demonstrating that various changes in the physiology of the plant can affect the expression of resistance to this aphid. A deficiency in one case (phosphorus) resulted in a higher resistance, and in another case (potassium) a lower degree of resistance, thus illustrating the complexities involved. One instance where a possible correlation between two factors existed was in the case of low temperature and potassium deficiency, both of which tended to reduce the degree of resistance. It is known that at low temperatures the accumulation of some ions by plants is reduced (Meyer and Anderson, 1952). Therefore, it is possible that at low temperature there 
also might have been a low level of potassium, resulting in a reduction of resistance. If such a case were found to exist, however, it would be difficult to separate cause and effect.

It seems probable that other undetermined environmental factors may also affect the expression of resistance to the spotted alfalfa aphid. There were cases where results obtained in one test did not conform as well as might be expected to those in a later test. Such discrepancies could not be explained completely on the basis of variations in temperature or one of the other factors studied. Also, in a given test, individual plants of the same resistant clone (especially in the case of C-902) sometimes varied in their apparent resistance, even though having the same genetic make-up. Individual leaves of approximately the same age on the same plant were also seen to vary. While this might be partly attributed to a differential reaction of individual aphids, it does not seem too likely, since variation in aphid numbers between replications on susceptible Caliverde plants was always very small, indicating homogeneity of test aphids in regard to reproductive capacity and survival.

Individual leaves of the same plant varying in resistance would conform to observations of Harvey and Hackerott (1958), who demonstrated that in reciprocal grafting of resistant and susceptible plants the plant parts maintained their original resistance or susceptibility. Thus, the resistance condition seems to be locally produced rather than translocated from one part of a plant to another.

Environmental factors had a more pronounced effect on resistance in C-902 than in C-84, since the former varied from complete susceptibility to high resistance, depending upon the conditions. Resistance thus seems to be a rather unstable character in C-902, being in delicate balance with the environment. Thus, this clone is probably near the threshold level of aphid resistance under many conditions, so that small changes in the environment may have a pronounced effect on its resistance. On the other hand, C-84, having a higher degree of inherent resistance, is able to maintain its resistance under a wider range of conditions. Both resistant clones were affected by the same environmental conditions, however, and this indicates that the basis for their resistance is of the same nature, although some factor having a pronounced effect on the resistance of C-902 would, in most cases, be expected to have a less noticeable effect on C-84.

Apparently, the lower the degree of inherent resistance possessed by the plant the more it will be affected by environmental factors. Thus it would seem that the highly resistant plants, such as C-84, would be most dependable in the field because they would be expected to exhibit a high degree of resistance under most or all conditions encountered. In comparison, plants intermediate in resistance might lose their resistance under certain conditions. Aside from the effects produced by various physical factors in the environment, certain biological relationships may also affect plant resistance. For example, Stanford and McMurtry (1959) noted an apparent breakdown of the resistance in the intermediate type plants in plantings of Lahontan. A potential development of strains infesting the intermediate types was indicated. Pesho et al. (1960) found a biotype of the spotted alfalfa aphid that was capable of surviving and reproducing on several of the resistant parent 
clones of the variety Moapa. However, neither of these studies gave indications that serious consequences would result from the occurrence of biotypes.

Therefore, plants having an intermediate degree of resistance still can be considered to be of value. According to Painter (1954) plants showing even a very low degree of resistance may be effective under widespread planting, since a slight decrease in the reproductive potential of the insect on the resistant variety might upset the balance and result in a gradual decline of the population until it reaches a critical minimum level.

It is hoped that the results of this study will provide new clues for further investigations concerning the basic nature of host-plant resistance to the spotted alfalfa aphid. At this time, little more can be said concerning this than has already been mentioned by McMurtry and Stanford (1960). It still appears that resistance to this aphid is a rather complex physiological process which is sensitive to environmental changes. Plant nutrition in relation to resistance certainly seems promising for further study. The accumulation of such data, showing that certain factors alter the expression of resistance, may eventually provide enough evidence to lead to a hypothesis regarding the nature of the resistance.

\section{SUMMARY}

Resistance in alfalfa to the spotted alfalfa aphid, Therioaphis maculata (Buckton), was studied in relation to several environmental factors. These factors included temperature, light duration and intensity, soil moisture, plant mineral nutrition, and physiological age of host leaves. Two resistant parental clones of the variety Lahontan were studied in comparison with a susceptible variety, Caliverde. The two Lahontan clones showed a lower degree of resistance at low than at high temperatures. One clone, C-902, appeared to be completely susceptible at $50^{\circ}$ and $60^{\circ} \mathrm{F}$, but became progressively more resistant at higher temperatures. The other clone, C-84, maintained at least an intermediate degree of resistance even at $50^{\circ} \mathrm{F}$, and was usually immune to aphid infestation at temperatures of $68^{\circ} \mathrm{F}$ or higher. Aphid population build-up was highest at $85^{\circ} \mathrm{F}$ on susceptible Caliverde plants, highest at $71^{\circ} \mathrm{F}$ on $\mathrm{C}-902$, and highest at $50^{\circ} \mathrm{F}$ on $\mathrm{C}-84$. Thus, the optimum temperature for population increase was lowest for plants having the highest degree of resistance.

The decrease in expression of resistance at low temperatures was shown to be due mainly to a change in the resistant plant, which in turn affected aphid survival and reproduction. Only a few days' time was required for resistance to become reduced at low temperatures or regained at high temperatures. Fully expanded, mature leaves were shown to be capable of undergoing these changes in resistance, thus indicating a physiological rather than a morphological basis for resistance.

Under controlled conditions of alternating high and low temperatures, the mean rather than the high or the low temperature appeared to be the most important in controlling the degree of resistance expressed.

Differences in photoperiod apparently had no effect on aphid survival and reproduction.

C-84 and C-902 plants watered with phosphorus- or potassium-deficient 
nutrient solutions were significantly different in resistance from plants watered with complete nutrient solutions, while the susceptibility of the Caliverde plants was not significantly altered by these deficiencies. Phosphorus-deficient C-84 and C-902 plants became more resistant, while potassium deficiency resulted in the plants being less resistant. Plants watered with a nitrogen-deficient solution did not vary in resistance or susceptibility from plants watered with the nondeficient solution.

Of the environmental factors studied, it appears that temperature is the most important in modifying the expression of host resistance to the spotted alfalfa aphid under field conditions. The studies suggest that the resistance is associated with a physiological process which is sensitive to environmental factors, and that plants having an intermediate degree of resistance are more noticeably affected by these conditions than the highly resistant plants.

\section{ACKNOWLEDGMENTS}

I am particularly indebted to Dr. L. M. Smith for his encouragement, valuable suggestions, and constructive criticism throughout the period of research and during the writing of this paper. My sincere appreciation is extended to Dr. E. H. Stanford for his active participation and generous cooperation in this work, as well as for the time he devoted to reading the manuscript. I am also grateful to Dr. W. H. Lange for his valuable criticism and reading of the manuscript; to Dr. F. E. Strong for assistance in the statistical analyses; and to Mr. E. C. Carlson for his cooperation and advice partaining to the greenhouse studies. Finally, I deeply appreciate the cooperation and interest of many members of both the Entomology and Agronomy departments at the University of California, Davis. 


\section{LITERATURE CITED}

Bear, F. E., and A. Wallace

1950. Alfalfa, its mineral requirements and chemical composition. New Jersey Agr. Exp. Sta. Bul. 748. 32 pp.

Cartwright, W. B., R. M. Caldwell, and L. E. Compton

1946. Relation of temperature to the expression of resistance in wheats to hessian fly. American Soc. Agron. Jour. 38: 259-63.

DAHMS, R. G.

1948. Effect of different varieties and ages of sorghum on the biology of the chinch bug. Jour. Agr. Res. 76: 271-88.

DAhMs, R. G., and R. H. Painter

1940. Rate of reproduction of the pea aphid on different alfalfa plants. Jour. Econ. Ent. 33: 482-85.

Dickson, R. C., E. F. Laird, JR., and G. R. Pesho

1955. The spotted alfalfa aphid (yellow clover aphid on alfalfa). Hilgardia 24: 93-118.

Dobson, R. C., and J. G. WatTs

1957. Spotted alfalfa aphid occurrence on seedling alfalfa as influenced by systemic insecticides and varieties. Jour. Econ. Ent. 50: 132-35.

EMERY, W. T.

1946. Temporary immunity in alfalfa ordinarily susceptible to attack by the pea aphid. Jour. Agr. Res. 73: 33-43.

Graham, H. M.

1959. Effects of temperature and humidity on the biology of Therioaphis maculata (Buckton). University of California Publ. Ent. 16(2): 47-80.

Hackerott, H. L., T. L. Harvey, E. L. Sorenson, and R. H. Painter

1958. Varietal differences in survival of alfalfa seedlings infested with spotted alfalfa aphids. Agron. Jour. 50: 139-41.

HACKEROTT, H. L., and T. L. HARVEY

1959. Effect of temperature on spotted alfalfa aphid reaction to resistance in alfalfa. Jour. Eicon. Ent. 52: 949-53.

HARPAZ, I.

1955. Bionomics of Therioaphis maculata (Buckton) in Israel. Jour. Econ. Ent. 48: 668-71.

HARVEY, T. L., and H. L. HACKerotT

1956. Apparent resistance to the spotted alfalfa aphid selected from seedlings of susceptible alfalfa varieties. Jour. Econ. Ent. 49: 289-91.

1958. Spotted alfalfa aphid reaction and injury to resistant and susceptible alfalfa clones reciprocally grafted. Jour. Econ. Ent. 51: 760-62.

Hoagland, D. R., and D. I. ARNoN

1950. The water-culture method for growing plants without soil. University of California Agr. Exp. Sta. Cir. 347. 32 pp.

Howe, W. L., and O. F. SMITH

1957. Resistance to the spotted alfalfa aphid in Lahontan alfalfa. Jour. Econ. Ent. 50: $320-24$.

Johnson, C. M., and A. Ulrich

1959. Analytical methods for use in plant analysis. Calif. Agr. Exp. Sta. Bul. 766: $26-78$.

Kennedy, J. S., A. Ibbotson, and C. O. Booth

1950. The distribution of aphid infestation in relation to leaf age. I. Myzus persicas (Sulz.) and Aphis fabae Scop. on sugar beet and spindle. Ann. Appl. Biol. 37: $651-79$. 
Kennedy, J. S., K. P. Lamb, and C. O. Booth

1958. Responses of Aphis fabae Scop. to water shortage in host plants in pots. Ent. Exp. Appl. 1: 274-91.

Kennedy, J. S., and T. E. MitTler

1953. A method of obtaining phloem sap via the mouth parts of aphids. Nature 171: 528.

LEES, A. D.

1955. The physiology of diapause in arthropods. Cambridge Univ. Press. $150 \mathrm{pp}$.

1959. The role of photoperiod and temperature in the determination of parthenogenetic and sexual forms in the aphid Megoura viciae Buckton. I. The influence of these factors on apterous virginoperae and their progeny. Jour. Insect Physiol. 3: 92-117.

LINDEMANN, C.

1948. Beitrag zur Ernährungsphysiologie der Blattlaüsen. Ztschr. Vergl. Physiol. 31: 112-33.

Maxwell, F. G., and R. H. Painter

1959. Factors affecting rate of honeydew deposition by Therioaphis maculata (Buckton) and Toxoptera graminum (Rond.). Jour. Econ. Ent. 52: 368-73.

McMurtry, J. A., and E. H. Stanford

1960. Observations of feeding habits of the spotted alfalfa aphid on resistant and susceptible alfalfa plants. Jour. Econ. Ent. 53: 714-17.

MeYer, B. S., and D. B. ANDERSON

1952. Plant physiology. Van Nostrand Co., New York. 784 pp.

MiTTLER, T. E.

1957. Studies on the feeding and nutrition of Tuberolachnus salignus (Gmelin) (Homoptera, Aphididae). I. The uptake of phloem sap. Jour. Exptl. Biol. 34: 334-41.

1958. Studies on the feeding and nutrition of Tuberolachnus salignus (Gmelin) (Homoptera, Aphididae). III. The nitrogen economy. Jour. Exptl. Biol. 35: 626-38.

Nielson, M. W., and W. E. Curie

1959. Effect of alfalfa variety on the biology of the spotted alfalfa aphid in Arizona. Jour. Econ. Ent. 52: 1023-24.

Painter, R. H,

1951. Insect resistance in crop plants. Macmillan Co., New York. 520 pp.

1954. Some ecological aspects of the resistance of crop plants to insects. Jour. Econ. Ent. 47: 1036-40.

Pesho, G. R., F. V. Lieberman, and W. H. Lehman

1960. A biotype of the spotted alfalfa aphid on alfalfa. Jour. Econ. Ent. 53: 146-50.

SCHOENe, W. J.

1941. Plant food and mealybug injury. Jour. Econ. Ent. 34: 271-74.

SмIтн, R. F.

1959. The spread of the spotted alfalfa aphid, Therioaphis maculata (Buckton), in California. Hilgardia $28(21): 647-85$.

STANFORD, E. H.

1956. Aphid resistant alfalfa plants: Inexpensive control of spotted alfalfa aphid can be expected as result of plant breeding program to develop new varieties. Calif. Agr. 10(7): 3 .

Stanford, E. H., and J. A. MCMurtry

1959. Indications of biotypes of the spotted alfalfa aphid. Agron. Jour. 51: 430-31. 

The journal Hilgardia is published at irregular intervals, in volumes of about 600 pages. The number of issues per volume varies.

Subscriptions are not sold. The periodical is sent as published only to libraries, or to institutions in foreign countries having publications to offer in exchange.

You may obtain a single copy of any issue free, as long as the supply lasts, please request by volume and issue number from:
Agricultural Publications
207 University Hall
2200 University Avenue
Berkeley 4, California

The limit to nonresidents of California is 10 separate issues on a single order. A list of the issues still available will be sent on request. 